\section{Estudios previos a la intervención en la capilla de la antigua iglesia de San Miguel, en Morón de la Frontera (Sevilla)}

\section{Pre-intervention studies of the chapel dedicated to Virgen de la Antigua in the parish church of San Miguel, in Morón de la Frontera (Seville)}

Francisco Pinto Puerto

E. T. Superior de Arquitectura. Universidad de Sevilla*

José María Guerrero Vega

Arquitecto. Sevilla**

\section{Resumen}

Los problemas que aquejan a la pequeña capilla renacentista dedicada a la Virgen de la Antigua, en la iglesia parroquial de San Miguel de Morón de la Frontera, la han llevado a un estado de degradación cercano a la ruina. Al plantearnos la intervención sobre este edificio surgió la necesidad de conocer las causas de la inestabilidad estructural que llevó a su urgente apuntalamiento en 1998. Para ello entendíamos que no era suficiente tomar como punto de partida el estado actual del edificio y calcular sobre él los refuerzos necesarios. El precario estado en que se encuentra muestra, a simple vista, las cicatrices y huellas de un complejo devenir que debíamos descodificar, diseñando para ello una serie de trabajos de auscultación y reconocimiento. Todos estos trabajos nos han permitido conocer y comprender sus etapas constructivas y destructivas, esto es, contar con las referencias necesarias, aunque nunca suficientes, para la realización del proyecto de restauración arquitectónica.

Palabras clave: Análisis arquitectónico; análisis estratigráfico; arquitectura tardogótica y renacentista; restauración arquitectónica; s. XVı.

\section{Abstract}

The problems affecting the small Renaissance chapel dedicated to Virgen de la Antigua in the parish church of San Miguel in Morón de la Frontera have led to a state of decay verging on total ruin. When we addressed the intervention required by the building, we realised that we needed to know what had caused the structural instability which had led to urgent bracing in 1998. We knew that we could not simply take the current state of the building as our starting point for calculating the necessary reinforcements. The precariousness of its current state reveals the scars and traces of a complex fate which we would have to decode by designing and programming a series of examinations to arrive at a diagnosis. All of these processes have enabled us to identify and understand the various phases of construction and destruction, that is, to acquire the necessary - although never sufficient - references to conduct the architectural restoration project.

Key words: Architectonic analysis; stratigraphic analysis; late Gothic and Renaissance architecture; architectonic restoration; 16 th century.

\footnotetext{
* fspp@us.es

**jmariagv@arquitectosdecadiz.com
}

\section{INTRODUCCIÓN}

La iglesia de San Miguel Arcángel es la parroquia mayor de la población de Morón de la Frontera, en la provincia de Sevilla; un templo de tres naves y cuerpo de cuatro tramos, rematado por un crucero de dos tramos y cinco capillas en la cabecera. Estos espacios están cubiertos por interesantes bóvedas pétreas que muestran el tránsito de un lenguaje tardogótico, heredero de la magna hispalense, a un renacimiento desnudo y sobrio. El edificio se enriqueció con una importante intervención barroca que afectó a su fachada principal y torre, aportándole un carácter marcadamente monumental. Es un magnifico ejemplo del selecto grupo de edificios, dispersos por lo que fuera el arzobispado hispalense $e^{2}$, que forman lo que vienen a denominarse "gótico catedralicio"; a saber, pequeñas catedrales donde los maestros mayores del arzobispado proyectaron y difundieron el repertorio arquitectónico previamente experimentado en la de Sevilla. Dada la envergadura de los programas arquitectónicos desarrollados en estas parroquias mayores, muy pocas llegaron a concluirse, con lo cual se abrió a partir del segundo tercio del s. XVI un espacio para la inserción del nuevo y pujante lenguaje renacentista, dejando muestras de un interesante debate entre «lo moderno o gótico» y «lo antiguo o romano" que generó un rico mestizaje de formas y soluciones constructivas.

El edificio se construyó en la falda norte del elevado promontorio donde se asienta el recinto amurallado de la antigua alcazaba (Fig. 1). Su dilatado proceso constructivo (s. XV a XVIII), se produjo en paralelo a un importante desarrollo urbano de la zona en torno a la misma, donde se acumularon numerosas edificaciones adheridas a la parroquia. Esta inmersión en el caserío hizo que el templo se consolidara como un hito urbano lejano, cuya torre y cúpulas se elevaban sobre el perfil de la ciudad y cuya

\footnotetext{
El contenido de este artículo tiene como base los trabajos previos a la intervención desarrollados por una serie de técnicos de ámbitos disciplinares muy variados, coordinados a través de un contrato de investigación en el marco de FIUS (Fundación para la Investigación de la Universidad de Sevilla). Los autores de estos trabajos fueron: Francisco Pinto Puerto y José María Guerrero Vega (redacción y coordinación de trabajos previos), Roque Angulo Fornos (fotogrametría), José María Guerrero Vega (lectura paramental), Carolina Villa Pedrero y Araceli Rodríguez Azogue (excavaciones arqueológicas), Juan Carlos Pecero Espín (antropólogo), Jesús Mendoza Ponce (diagnóstico de bienes muebles), VORSEVI S.L. (sondeos y caracterización de materiales), Juan Carlos Gómez de Cózar y Rosa Benitez Bodes (análisis estructural). Los trabajos fueron promovidos por el Arzobispado Hispalense y financiados por la Delegación de Sevilla de la Consejería de Cultura de la Junta de Andalucía, dentro del programa AM30-PROGRAMA OPERATIVO FEDER 2007-2013.

2 El Arzobispado hispalense ocupaba hasta bien entrado el s. XIX lo que actualmente son las provincias de Sevilla, Huelva, y buena parte de Cádiz y Málaga.
} 

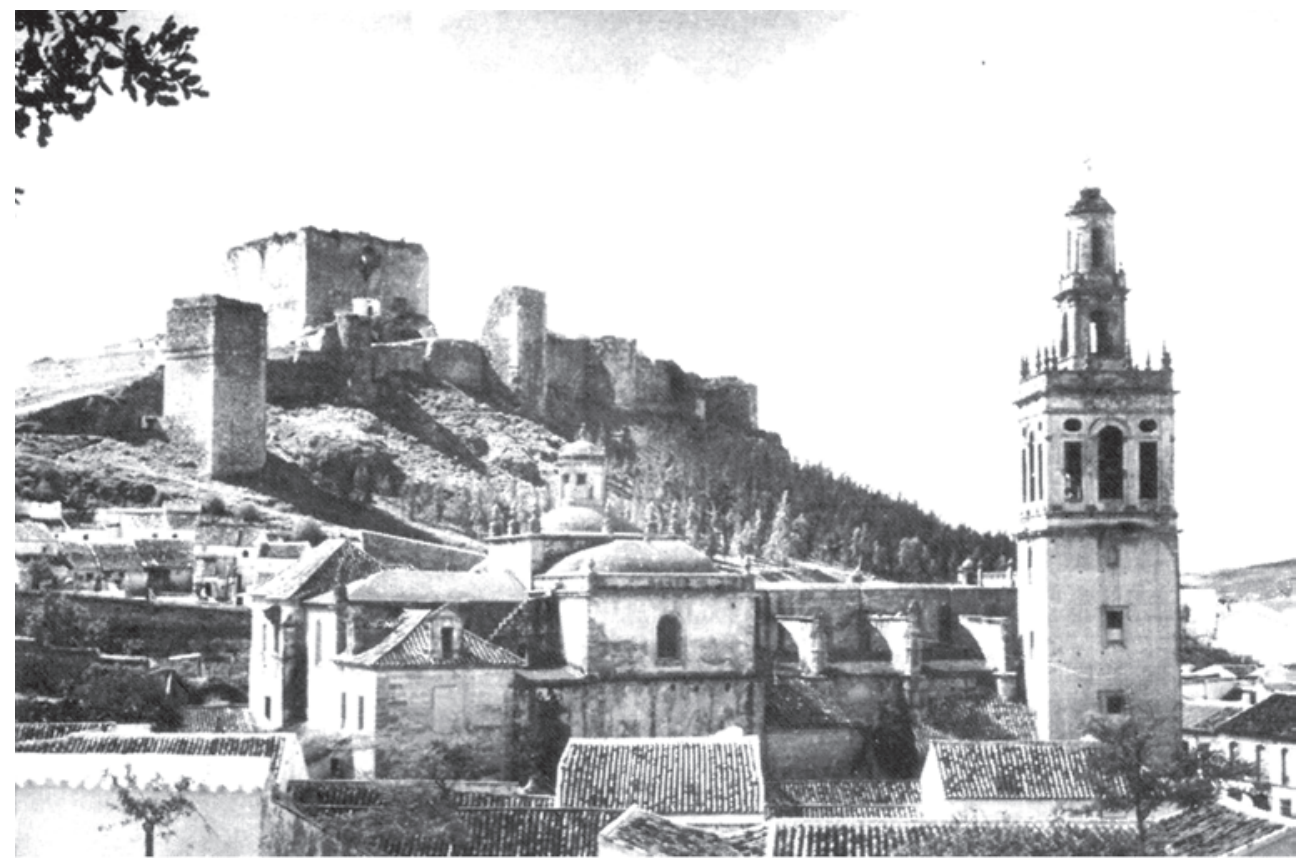

Fig. 1. Iglesia de San Miguel y el cerro del Castillo de Morón de la Frontera a mediados del s. xx. (Morón de Castro, 1995)

fachada principal era la única que se podía contemplar de cerca desde la pequeña plaza ubicada a sus pies.

En la actualidad, sin embargo, la iglesia se encuentra desvinculada de las edificaciones circundantes debido a un proceso de vaciado urbano que comenzó a mediados del siglo pasado y concluyó en la década de los setenta con la demolición de las últimas edificaciones anexas a sus muros. Este proceso de limpieza selectiva no sólo afectó a su estructura material, sino a su relación con la ciudad, produciéndose en la actualidad un extrañamiento de ésta respecto al edificio.

Los esfuerzos de varios colectivos por recuperar su papel en la ciudad, y los importantes trabajos de investigación desarrollados sobre el edificio, no han encontrado aún una respuesta adecuada en un plan de inversiones para su restauración, marcada por su magnitud y complejidad. No fue hasta hace pocos años que las instituciones municipales y autonómicas volvieron a mostrar interés en el edificio. Aquejado en la actualidad por graves problemas de conservación, se planteó en el año 2005 una planificación global de las intervenciones necesarias para su recuperación, cuya primera fase está redactada y a la espera de financiación. Mientras tanto, las actuaciones sólo se están produciendo a través de inversiones puntuales como la destinada a la restauración de la capilla de Nuestra Señora de la Antigua, anexa al muro norte del templo ${ }^{3}$ (Fig. 2). La redacción de

\footnotetext{
${ }^{3}$ Estos trabajos de restauración, pendientes de comenzar cuando presentamos
} este texto, serán financiados por la Diputación de Sevilla. este proyecto ha motivado el conjunto de estudios previos que ahora se presentan.

La razón de intervenir en esta parte del templo se debe a la urgencia de su estado estructural y al interés arquitectónico que posee la fachada norte del templo en la que se encuentra la capilla, pues en ella quedan visibles los elementos más antiguos del conjunto, que se remontan a los inicios del s. XV.

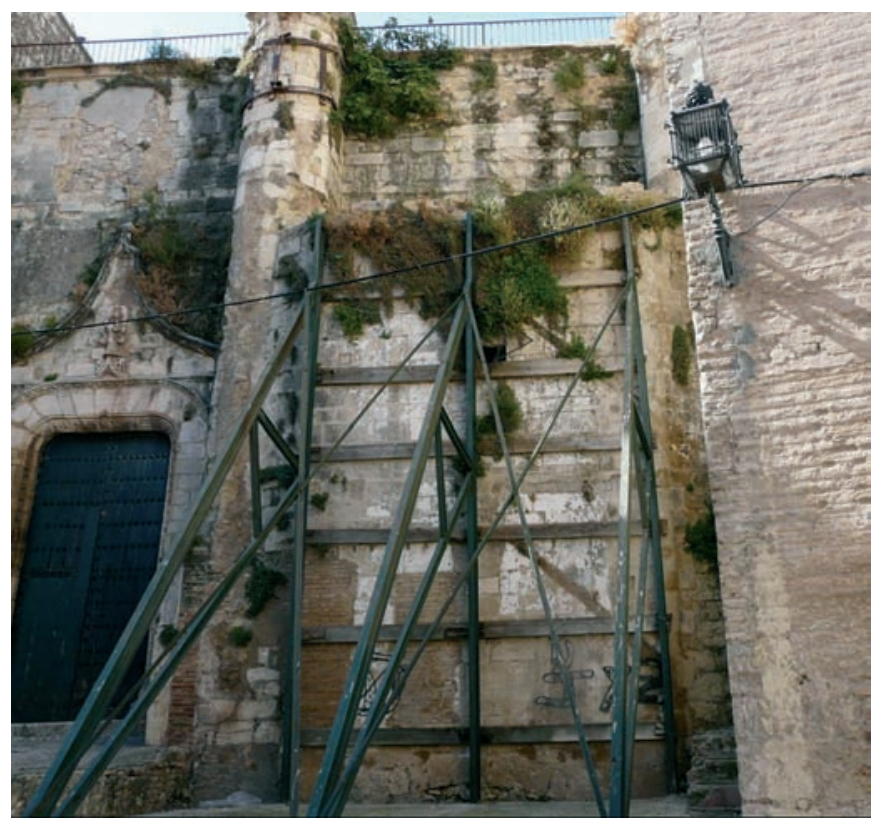

Fig. 2. Vista de fachada norte de San Miguel y los apuntalamientos de la capilla (2009) 


\section{METODOLOGÍA}

Teniendo en cuenta la dualidad de las urgencias planteadas, a saber, solucionar una estructura arquitectónica en crisis por un lado y recuperar su valor como documento histórico por otro, los trabajos previos han tenido como objetivo:

- Obtener un conocimiento sintético de su evolución, identificando el número de fases constructivodestructivas a lo largo de la vida de la capilla y el edificio al que se adosa, para descubrir el origen de las graves lesiones estructurales detectadas y poder proyectar la intervención más adecuada.

- Elaborar una descripción y documentación precisa, a modo de registro, de la situación de los paramentos, huellas y restos ahora observables, que completaremos con aquellos otros datos que se obtendrán durante los trabajos de restauración. Esto quiere decir que el proceso ahora iniciado debe quedar abierto.

Para alcanzar estos objetivos se planificaron los siguientes trabajos:

- El dibujo del edificio, entendido como instrumento de conocimiento del mismo, va más allá de una mera traducción gráfica inmediata de un registro métrico. Por el contrario, se trata de un proceso donde se realiza una lectura comprensiva, nunca automática, de los elementos constitutivos del edificio, que posteriormente serán expresados gráficamente en unas imágenes, generalmente unas proyecciones ortogonales. La rigurosidad, dentro de la subjetiva interpretación que todo dibujo supone, nos la garantiza el uso de sistemas de captura métrica basada en la fotografía: fotogrametría y homologías, sistemas ya habituales en este tipo de trabajo. La imagen perspectiva fotográfica es ortogonalizada mediante diversos sistemas que nos permiten medir y dibujar sobre ella con suficiente precisión, pero sobre todo permiten mantener vivo el dibujo, pues basta sustituir la imagen fotográfica por otra actual y volver a operar sobre ella para compararla con lo que ya habíamos elaborado e introducir las matizaciones y diferencias percibidas, o incorporar imágenes mucho más antiguas que puedan surgir de algún cajón de archivo, procesándolas de igual modo que las anteriores. Esta interacción con la imagen gráfica, ahora del todo posible, libera al dibujo de esa fecha de caducidad que supone su conclusión, convirtiéndolo de paso en una buena base de datos de la propia evolución del edificio.
El dibujo en soporte digital permite mantener abierto el proceso de análisis sobre el edificio, transformable en función de los contenidos, o mejor, de las futuras investigaciones.

- El registro, inventario y verificación de las fuentes documentales nos proporcionó una relación cronológica de acontecimientos en la que se evidenciaba una serie de imprecisiones debido, fundamentalmente, a hipótesis contradictorias elaboradas por la historiografía. Esta circunstancia se agravaba en aquellos aspectos concernientes a la relación entre la capilla y la torre, donde se habían perdido algunas fuentes originales y la información quedaba diluida en una cadena de interpretaciones y citas literales.

- El análisis de las características materiales de los elementos constructivos se realizó mediante la toma de muestras y la extracción de testigos. Se pretendía identificar las diferentes técnicas y materiales que forman su masa y desvelar su estructura interna, imperceptible visualmente. Considerábamos que parte de los problemas estructurales del edificio tienen su origen en la composición de sus elementos constructivos, que sólo se intuían a través de indicios o huellas exteriores como grietas o deformaciones.

- El estudio arqueológico de las estructuras subyacentes consistió en la realización de dos catas que permitieron establecer los distintos niveles de ocupación y el reconocimiento de las cimentaciones y el terreno. La superficie excavada se redujo a lo imprescindible debido al riesgo que suponía demoler una losa de hormigón de gran espesor, colocada exteriormente como cimiento del apuntalamiento realizado en 1998. Las inevitables vibraciones que producía la apertura de estas catas afectaban a la precaria estructura de la capilla. A pesar de ello, la información obtenida era imprescindible para valorar el resto de las observaciones y análisis.

- La lectura estratigráfica-constructiva de los paramentos con criterios arqueológicos permitió un registro directo y sistemático de las huellas detectadas. Se identificaron las diferentes unidades estratigráficas (UE), agrupadas por actividades (A) y por relaciones de contemporaneidad, anterioridad o posterioridad. Con ello se obtuvo una descripción pormenorizada de las huellas presentes en los paramentos del edificio y se interpretó su secuencia temporal, concretando fechas de acontecimientos mediante la información obtenida de las fuentes documentales. 


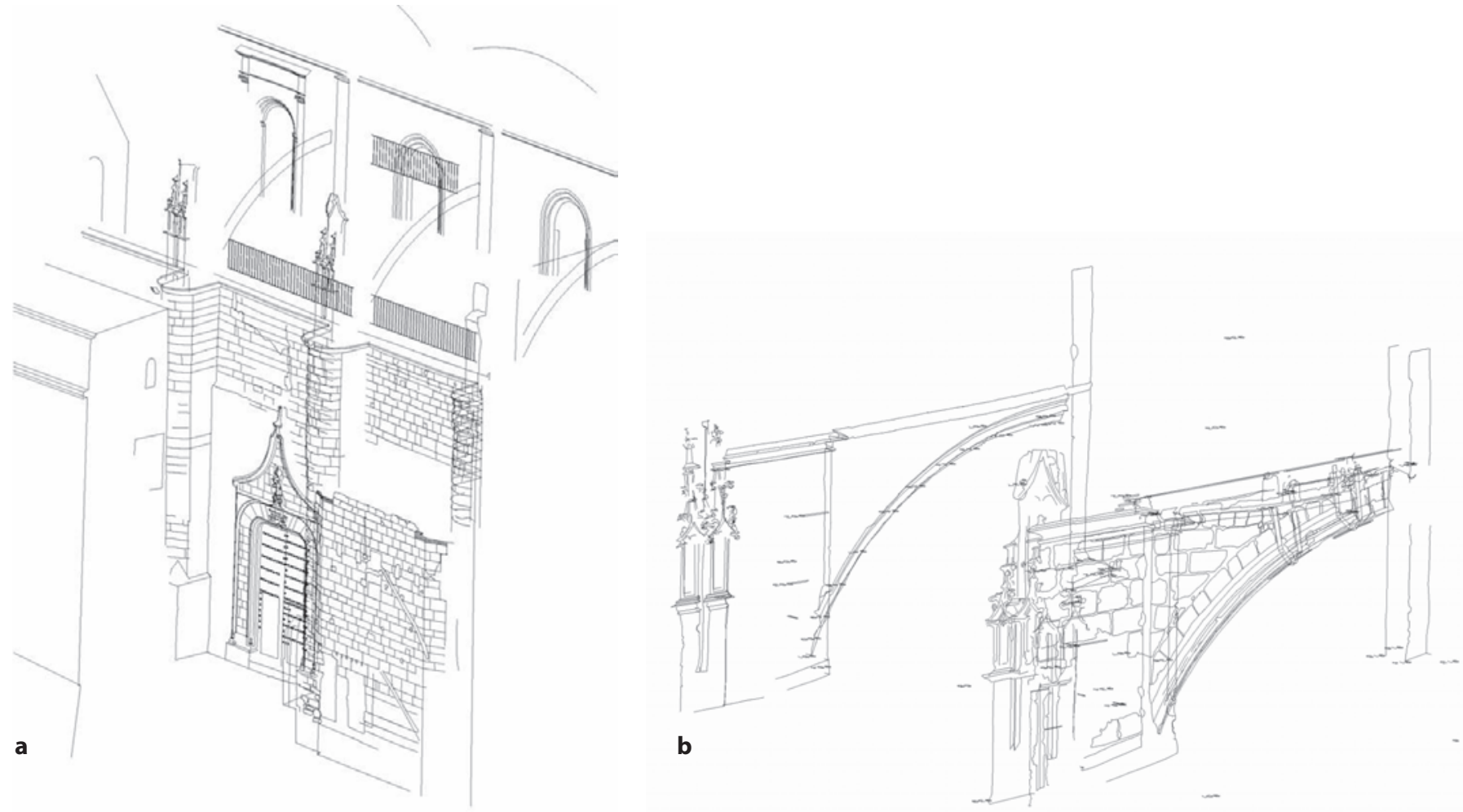

Fig. 3. Axonometrías de las fotogrametrías realizadas por el CSIC y las completadas en el levantamiento. (Dibujos de A. Almagro, 1998; y R. Angulo, 2008)

El resultado de esta lectura fue esencial para valorar la magnitud de las transformaciones y desvelar el origen de los problemas estructurales que se percibían, posibilitando la comprobación y cálculo del comportamiento estructural del conjunto. Estos últimos trabajos consistieron en la elaboración de distintos modelos virtuales del edificio, basados en las situaciones de cada una de las etapas analizadas. Estos modelos fueron sometidos a cálculos y análisis estructurales con objeto de comprobar su comportamiento y detectar las variaciones de la estabilidad y la evolución de las cargas y tensiones hasta llegar al estado actual.

\section{PROCESO}

Contábamos como punto de partida para nuestro trabajo con una completa fotogrametría realizada por el CSIC en el año $1998^{4}$. Esto nos permitió medir y dibujar con precisión los graves desplomes del muro exterior de la capilla y las deformaciones de los arbotantes que gravitan sobre los estribos, los cuales sirven de pared lateral a la capilla (Fig. 3). Completamos estos datos con una nueva captura mediante fotogrametría de los dos arbotantes

${ }^{4}$ Este levantamiento gráfico en 3D fue realizado por la Escuela de Estudios Árabes (CSIC), dirigido por A. Almagro Gorbea y encargado por la Dirección General de Bienes Culturales de la Junta de Andalucía. La fotogrametría recogía todas las bóvedas interiores y los paramentos exteriores del templo, quedando incompleto sólo el paramento norte debido a la dificultad para la toma de datos. existentes sobre la capilla, y el levantamiento con medios directos del interior de la capilla que aún está ocupado por un denso apuntalamiento de madera (Fig. 4). Con esta toma de datos elaboramos posteriormente una sección transversal del templo pasando por el eje de la capilla, proyectada hacia los pies y la cabecera (Fig. 5). Quedaba así definido uno de los planos característicos de este tipo de edificio, el transversal, donde se visualiza con claridad el sistema de distribución de cargas y esfuerzos góticos. Se

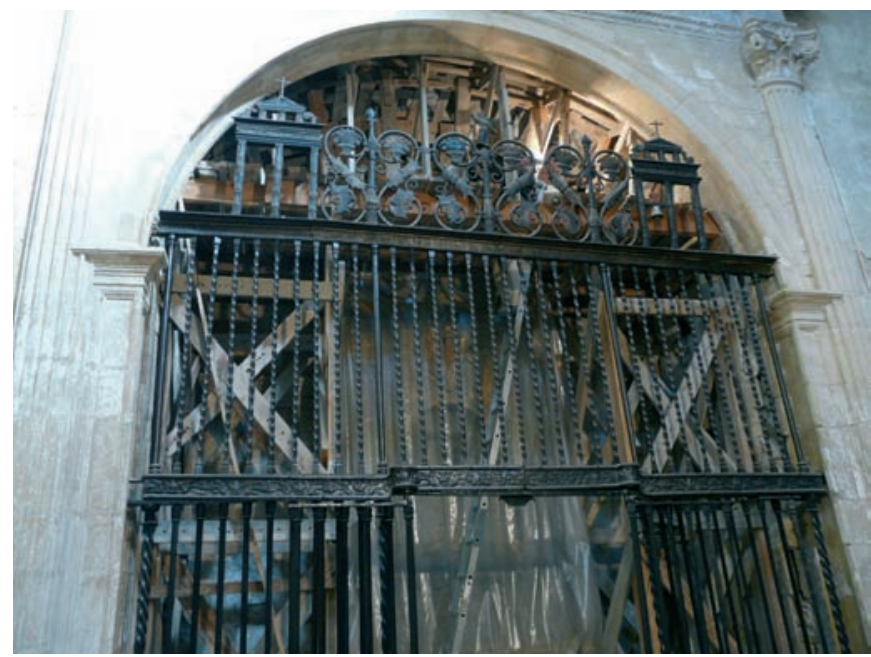

Fig. 4. Vista de capilla de la Antigua desde la iglesia y el apuntalamiento interior (2009) 

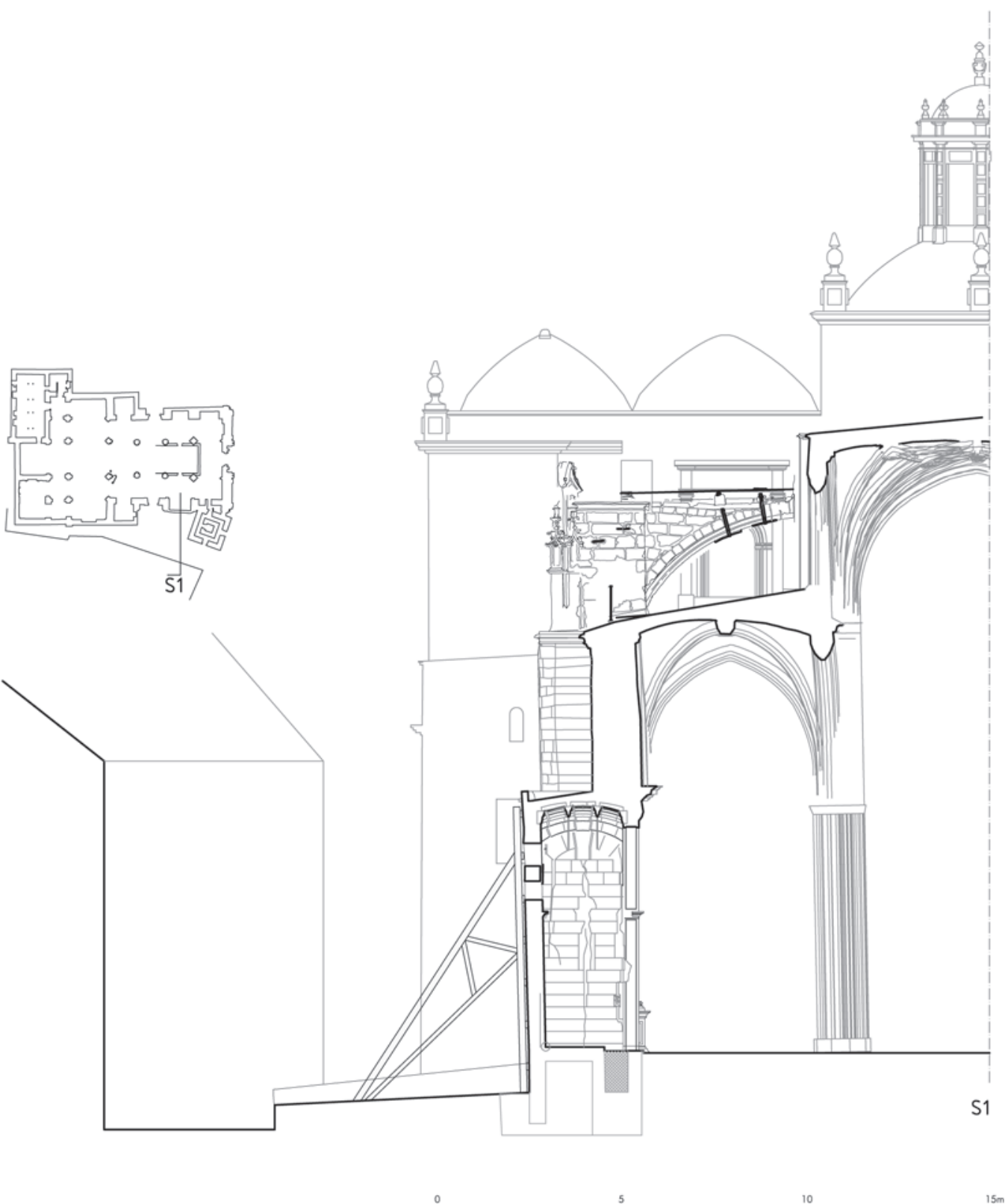

Fig. 5. Sección transversal de la iglesia y la capilla a partir de los datos fotogramétricos. (Dibujo de los autores, 2007)

obtuvo por primera vez la imagen de la deformación y rotura del edificio, donde las grietas adquieren un papel destacado.

La imagen construida ofrecía por sí los ingredientes necesarios para una comprensión del estado de deformación que posteriormente se habría de explicar matemáticamente a través de un sistema de cálculo informatizado ajeno a la propia manera de hacer de la época, pero sumamente útil para cuantificar las acciones que se desarrollarán en el proyecto de intervención.

A su vez realizamos otros dibujos más abstractos que nos permitieron contar con un sistema de referencia espacial donde ubicar nuestras observaciones. Estos esquemas mostraban una red espacial de líneas con la que atrapar y ubicar la información elaborada en cada uno de los estudios. En este caso la red no es isótropa, sino que parte del análisis previo del edificio. Las líneas identifican los planos transversales al edificio que son los principales de carga, y los longitudinales que definen la secuencia de las naves desde los pies (punto donde se inicia la reforma gótica) hasta la cabecera (última en levantarse) (Fig. 6). Cada dato queda asociado a un plano, una línea o un punto, signado con varios dígitos, formando así un código de identificación espacial. En el caso de la capilla, está 


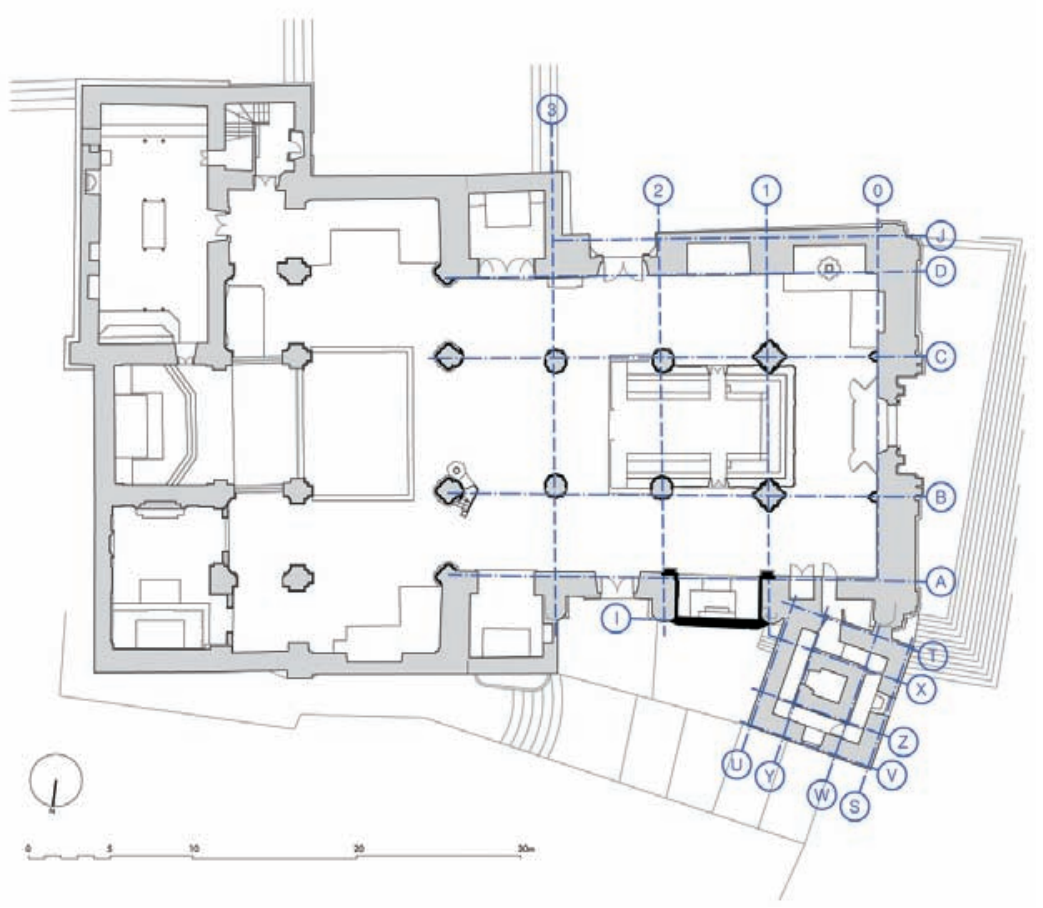

Fig. 6. Sistema de referencia espacial sobre la planta de la iglesia de San Miguel. (Dibujo de los autores, 2006)

formada por los planos A, I, 1 y 2. La bóveda y suelo son AI12, los estribos I1 e I2, la portada A12, o el plano de fondo I12. Para diferenciar dos planos superpuestos hemos añadido un apellido AI12-bov o AI12-pav.

La historia y evolución de la iglesia de San Miguel de Morón está documentada y analizada en varios trabajos anteriores, donde podemos encontrar las fuentes más importantes escritas, iconográficas y gráficas ${ }^{5}$. A través de estas fuentes elaboramos una cronología que se configura como una red, en este caso temporal, y que resumimos en los acontecimientos más destacados en la siguiente relación:

1403. Primeras noticias sobre la construcción de la iglesia de San Miguel. Se cita al maestro Johan Martín, por un pago por labrar la iglesia (Morón de Castro 1995, 31).

1504. Terremoto y ruina de la iglesia (Ibíd., 54).

1508-1526. Se cubren las naves laterales y el primer tramo de la nave central y el primer par de arbotantes, bajo la dirección de Antón Ruiz (Ibíd., 73).

1526 y 1528 . Se concluye el segundo tramo de la nave principal bajo la dirección de Diego de Riaño (Ibíd., 78).

\footnotetext{
5 Entre los trabajos de documentación histórica destacamos por su carácter monográfico, el de M. F. Morón de Castro (1995), a la que añadimos el análisis más sistemático y estructurado respecto a lo arquitectónico realizado en la tesis doctoral de J. A. Fernández Naranjo (2004).
}

1529. En este año se estaban acabando seis arbotantes de la iglesia y se cierra la bóveda del tercer tramo de la nave principal. El maestro mayor de la obra era Diego de Riaño y en este momento Martín de Gaínza pasa a ser el aparejador. La obra queda parada (Ibíd., 79-80).

1538. Fundación del patronazgo de la capilla de la Virgen de la Antigua por doña Mencia Osorio Morejón (Morilla 2006, 82).

1550. Martín de Gaínza da trazas para la iglesia de San Miguel y «el campanario que se ha de hazer encima de la puerta prençipal de la dicha iglesia...» (Morón de Castro, 89).

1591. La fábrica de la iglesia adquiere el sitio de una sepultura otorgada a los Auñones, ubicada detrás de su capilla en terrenos lindantes a la torre (Ibíd., 158).

1676. Quedan abiertos los huecos de la caña de la torre. Se describe el carácter y dimensión de la obra (Ibíd., 162).

1680. Estaba acabado el campanario. Hubo un gran terremoto que produce roturas en el campanario y en las bóvedas de la iglesia (Ibíd., 163).

1688. Se encala y se coloca la solería del templo. Se traslada el órgano desde el muro de la fachada al lateral del coro, frente a la capilla de la Antigua (Ibíd., 168).

1700. Se finalizan las obras de la torre (Ibíd., 177).

1717. Se demuelen parte de los muros del lado sur y del testero de los pies del templo para su reconstrucción. Se 


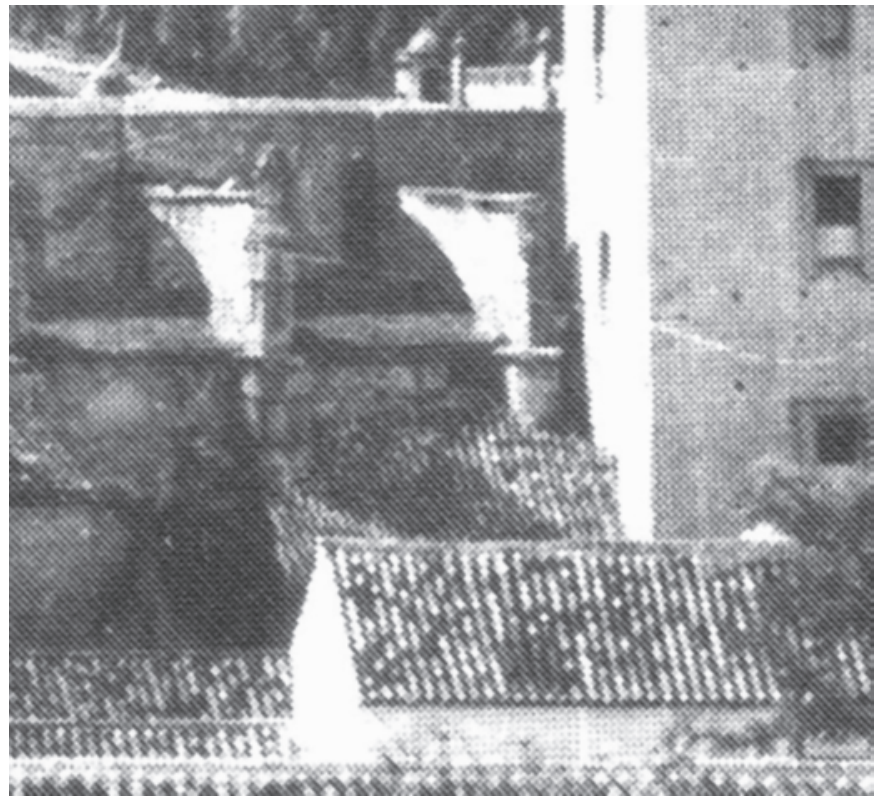

Fig. 7. Detalle de la figura 1. Se observa la cubierta de tejas de la edificación anexa a la capilla. (Morón de Castro, 1995)

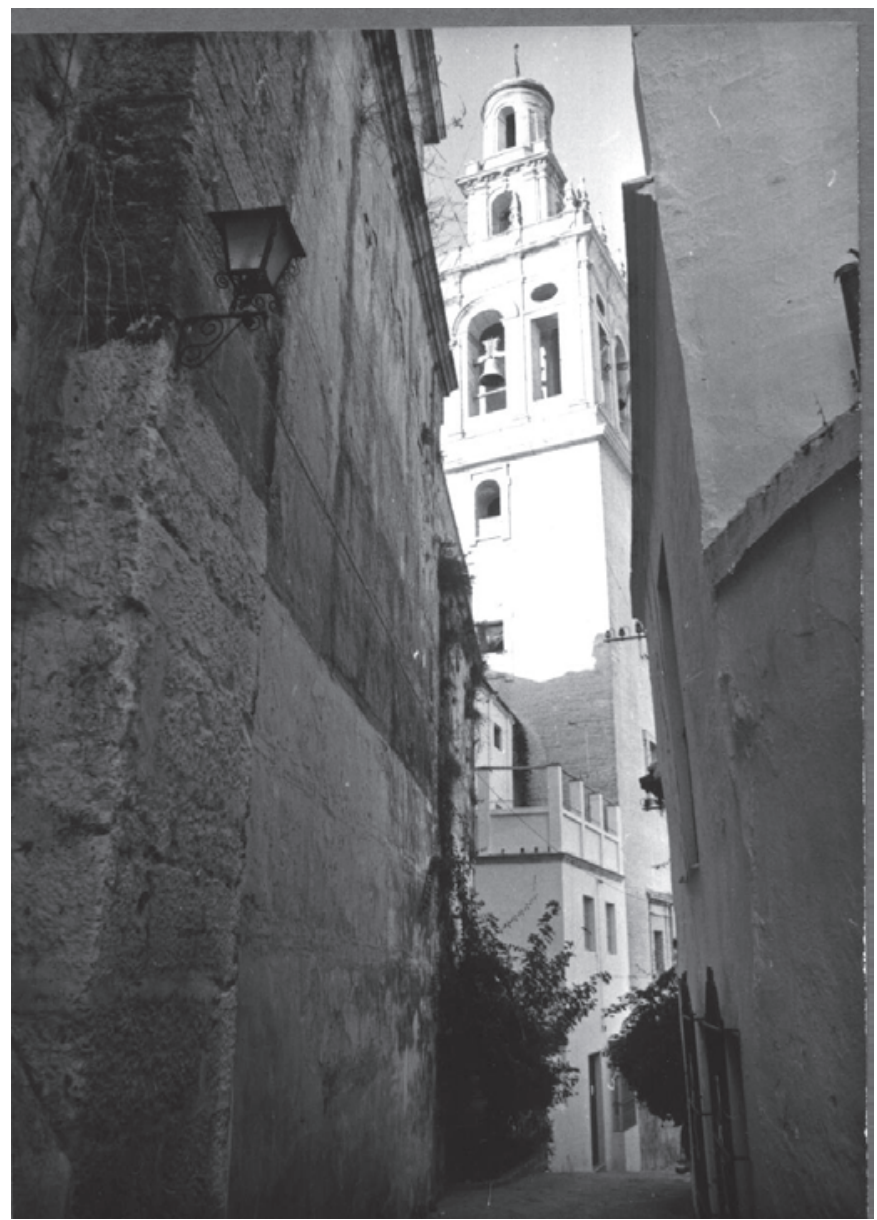

Fig. 8. Imagen de la casa anexa a la capilla y torre de San Miguel desde la calle Siete Revueltas en 1967. (Imagen facilitada por J. A. Fernández Naranjo. Archivo de R. Manzano)

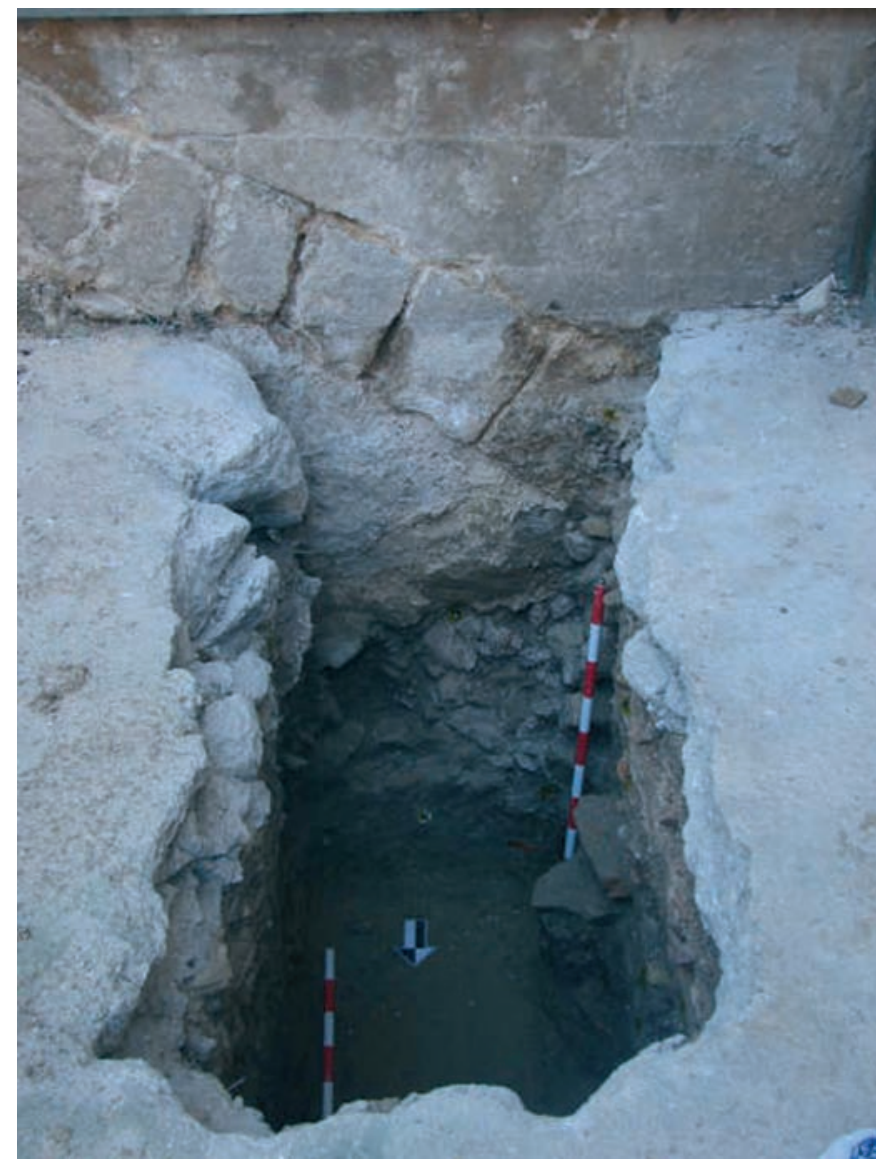

Fig. 9. Cata $n^{\circ}$ 2. Registro de la cimentación de la capilla. Se verifica la continuidad del arco hasta el cimiento del estribo

construye un cuarto aledaño a la capilla de la Antigua para los curas semaneros, junto a la torre y comunicado con la iglesia a través de la capilla (Ibid, 178).

1755. Terremoto de Lisboa. Informe de Pedro de Silva, donde constata que fueron las tres bóvedas más antiguas de la nave central, es decir, las del primer tramo las que sufrieron los mayores desperfectos (Ibíd., 182).

1758. Pedro Silva restaura las tres bóvedas más antiguas de la nave central (Ibíd., 182).

1768. Se realiza el retablo de la Virgen de la Antigua, se estofa la reja y se decora la capilla, según consta en una cartela escrita en el friso de la reja.

1789. Inscripción en una lápida de enterramiento en la capilla de la Virgen de la Antigua.

1841. Inscripción en una lápida de enterramiento en la capilla.

1924. Fotografía del lado norte de la iglesia sin los refuerzos metálicos (Morilla 2006, 50).

1925. Reparación del arbotante y el estribo mediante elementos metálicos externos. Se documenta mediante la fecha inscrita en el perfil metálico, lo que indica el momento más antiguo posible de este reparo. 


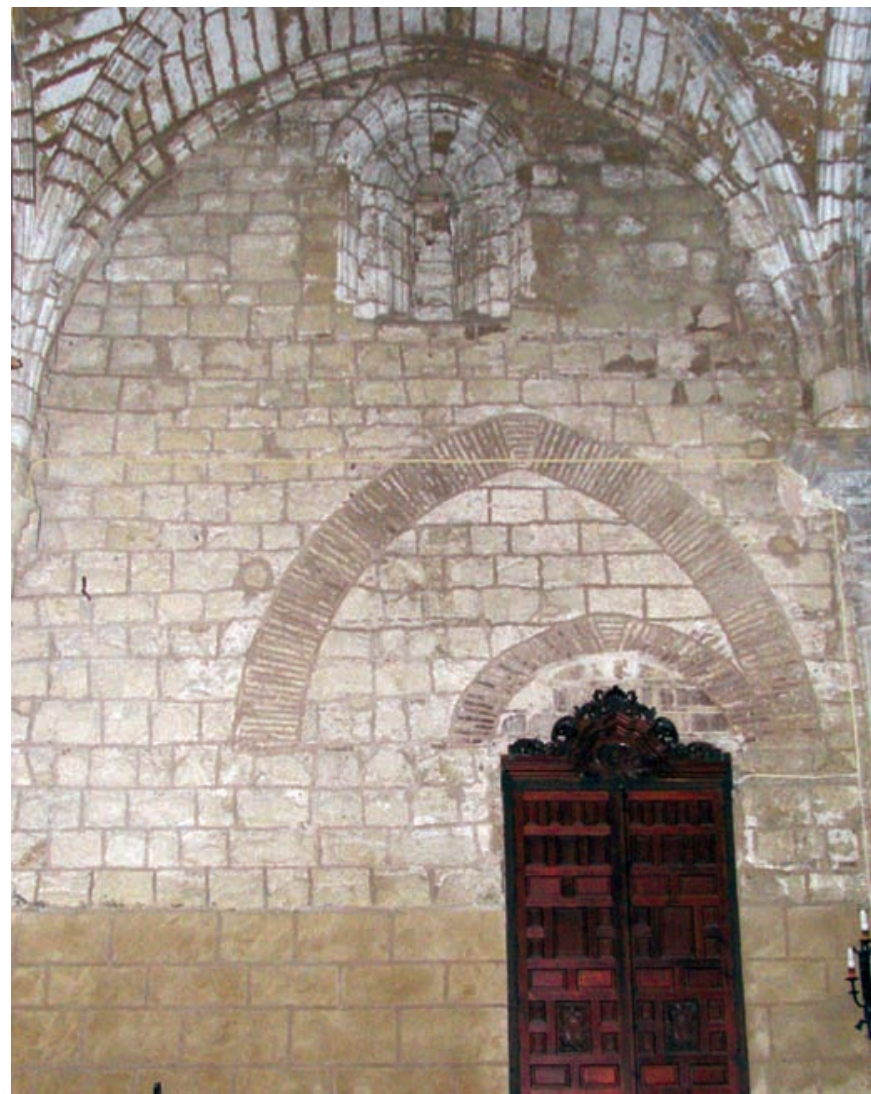

Fig. 10. Arco de descarga en el paramento A01 para construir el cimiento de la torre

1925. Imágenes del interior de la capilla en buen estado. Se observa también la cancela practicada en la reja para acceder a la casa del párroco (Morilla 2006, 33).

1930. La heredera de la patrona de la capilla de la Antigua (doña María Gracia de Montestruque Auñón) reclama al arzobispado hispalense que se deje de usar la capilla como almacén de trastos, se limpie y se rehabilite para el culto a la Virgen de la Antigua (Morilla 2006, 82).

1936. En julio se destruye el órgano, viéndose afectado el tramo correspondiente, justo entre los pilares frente a la capilla tratada (Ibid, 96).

1953. Fotografía en la que se aprecia la cubierta inclinada más alta de la casa junto a la capilla ${ }^{6}$ (Fig. 7).

1956. Proyecto para la casa del coadjutor de la parroquia de Aurelio Gómez Millán ${ }^{7}$ (Fig. 8).

1967. Se demuele la casa de los curas junto a las otras dependencias anexas (Morón de Castro 1995,183).

\footnotetext{
${ }^{6}$ Fototeca de la universidad de Sevilla. Num. Registro 3-13125.

Archivo Histórico de la Fundación para la Investigación y difusión de la Arquitectura. Proyecto de casa para el coadjutor de la parroquia de San Miguel de Morón de la Frontera (Sevilla). Arquitecto Aurelio Gómez Millán. 1956. Exp. 46297 y $44550-60-61$
}

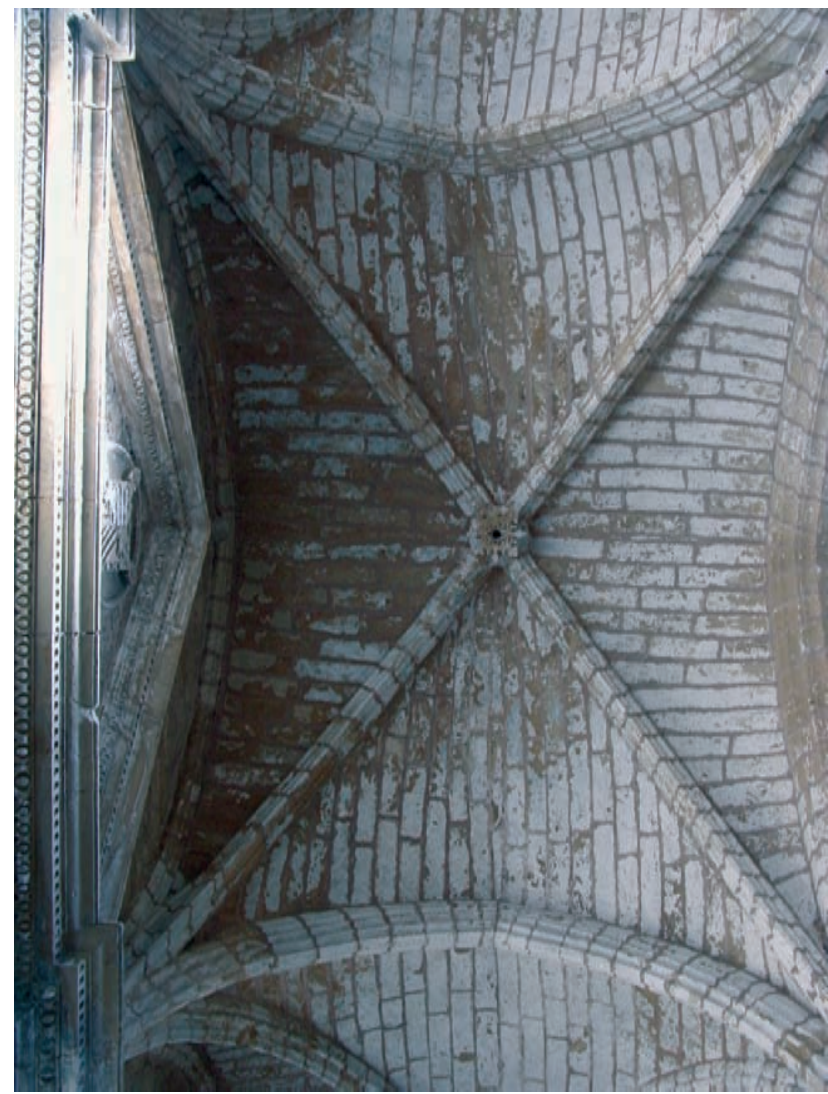

Fig. 11. Bóveda cuatripartita del tramo de la nave lateral sobre la capilla AB23

1969-82. Se cierra la iglesia al culto por su mal estado. Se inicia la restauración del templo dirigida por el arquitecto Rafael Manzano Martos. Entre los trabajos realizados se encuentra la demolición de las edificaciones colindantes, entre ellas la edificación junto a la capilla y torre (Fernández Naranjo 2004, 77-83).

1970. Se declara la iglesia Monumento Histórico Artístico.

1998. Se instala un apuntalamiento metálico en el muro de la capilla para evitar su ruina. Campaña de ensayos, caracterización de materiales, análisis de patologías y estudio geotécnico del subsuelo.

El resultado de este complejo devenir histórico es un conjunto formado por varias unidades edificatorias: una capilla adosada al muro del segundo tramo de la nave lateral norte del templo, la propia nave compuesta de arbotantes y estribos, una torre adosada al primer tramo, y una desaparecida construcción anexa a su vez a la parte exterior de la capilla y la torre, que son las zonas afectadas por la intervención que hemos proyectado.

En el caso de la cimentación, las calicatas acometidas en el estribo I3, en los estudios geotécnicos de 1998, mos- 

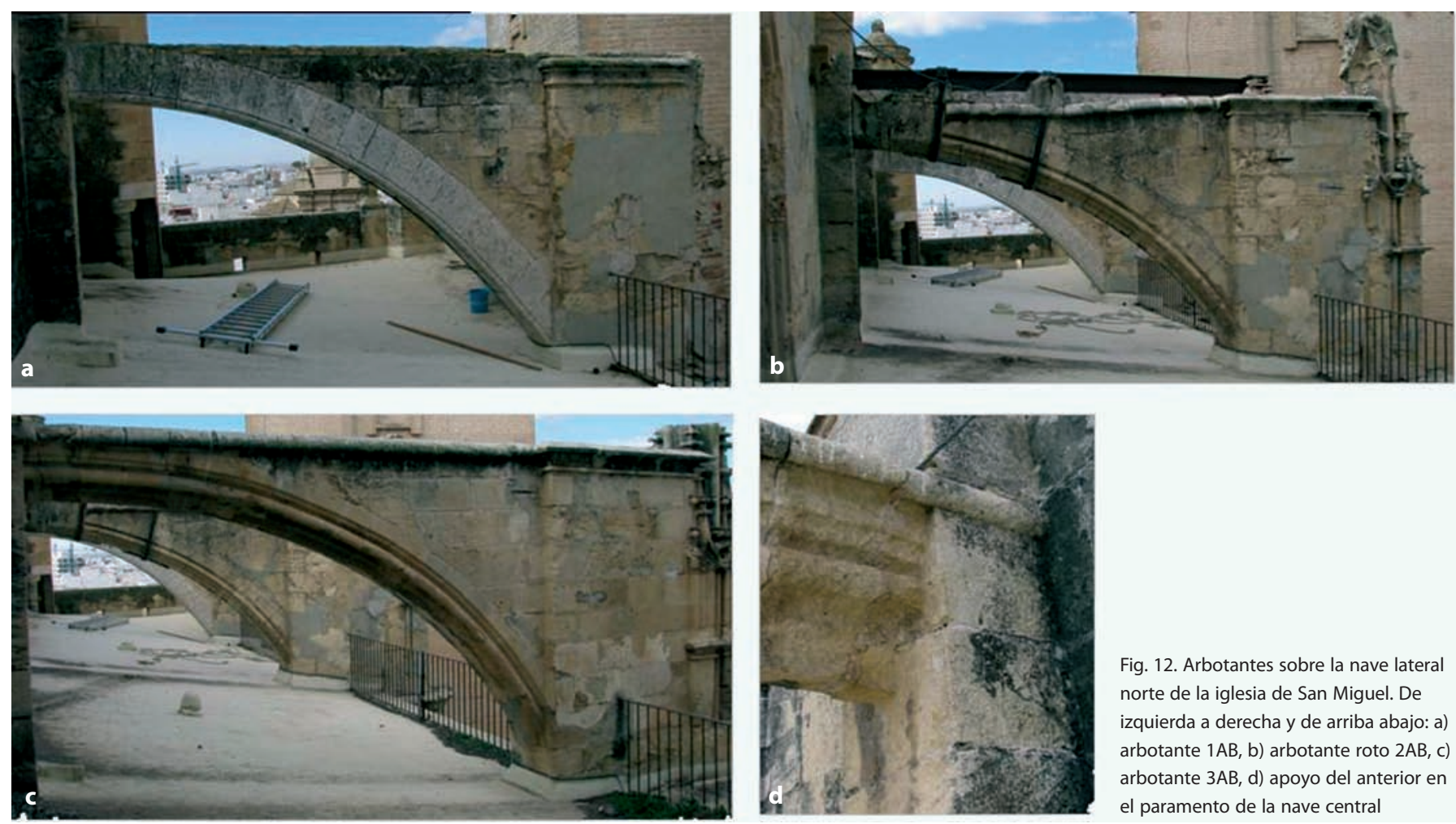

Fig. 12. Arbotantes sobre la nave lateral norte de la iglesia de San Miguel. De izquierda a derecha y de arriba abajo: a) arbotante $1 A B, b$ ) arbotante roto $2 A B, c$ ) arbotante $3 A B, d$ ) apoyo del anterior en el paramento de la nave central

traban cómo la fábrica del estribo continuaba sin alteración hasta una profundidad de $45 \mathrm{~cm}$ por debajo de la cota de solería interior. A partir de esa profundidad y hasta una profundidad de $80 \mathrm{~cm}$ aparecían masas irregulares de argamasa que sobresalían entre 21 y $39 \mathrm{~cm}$ de la pared del estribo, asentadas parcialmente sobre una roca de yeso. Las excavaciones arqueológicas realizadas en los actuales trabajos previos demuestran la existencia de dos cimientos parecidos para los estribos I1 y I2, en los que se apoya la capilla. Estos cimientos son algo más profundos, salvando así el desnivel en descenso del terreno hacia el oeste, tal como se observa actualmente en la calle Siete Revueltas a la que da fachada. En estas excavaciones se verificó también la existencia de un arco de descarga hacia los estribos bajo el muro exterior de la capilla (Fig. 9). Esta solución permitió realizar la capilla eludiendo nuevas cimentaciones sobre un terreno ocupado por varios enterramientos, que se remontan a la primera fundación del templo.

La prospección realizada en 1998 permitió también detectar la profundidad de la cimentación de la torre anexa al primer tramo del templo, en contacto directo con la capilla, que tiene unos $290 \mathrm{~cm}$ de profundidad respecto al nivel de solería interior. Sobre este plano de asiento se eleva hasta $210 \mathrm{~cm}$ un cimiento que supera en ancho a la torre en 175 centímetros por cada lado. Esta cimentación está formada por una compacta argamasa con rocas y restos cerámicos, sobre la que se eleva un primer nivel de la torre formado por hiladas de sillares regulares de piedra que asciende unos $80 \mathrm{~cm}$, quedando en parte vistos. Sobre este zócalo pétreo se construyó la caña de la torre en fábrica de ladrillo macizo. La cimentación de la torre penetró en la iglesia, provocando una nueva reforma del paramento norte para poder trabajar sobre él mediante la introducción de un arco de descarga que queda actualmente a la vista desde el interior del templo (Fig. 10). Esta solución evitó descalzar la fábrica gótica al recibir bajo ella la nueva cimentación, aunque produjo algunas lesiones que afectaron a la cercana capilla. Quizás la más visible es el desnivelado del arbotante entre el primer y segundo tramo de la nave lateral norte, por lo que tuvieron que rehacerlo.

En cuanto al templo, el tramo que más nos interesa es el afectado por la construcción de la capilla, esto es, el que cubre el espacio AB12. Está formado por una bóveda cuatripartita construida con nervios diagonales, arcos perpiaños hacia los tramos contiguos, formeros en su unión con el muro A y un toral hacia la nave central, con una clave central de escasa entidad (Fig. 11). Esta bóveda enjarja con los pilares B1 y B2, y acomete sobre ménsulas en el paramento $\mathrm{A}$, al igual que las existentes en el resto de la nave. Estas ménsulas fueron anuladas por la construcción del frontón que remata la portada de la capilla, quedando sólo sus enjarjes. 
La bóveda de diagonales, que cubre el tramo que estamos tratando, es parte de la reforma gótica del templo original que aprovechó el muro exterior norte (A). Sus dovelas y plementería son de piedra, al igual que los pilares y los enjarjes. El muro A sobre el que apoya, que pertenecía a la fábrica más antigua, es de mampuestos irregulares. De él sólo queda a la vista en este tramo la parte sobre el arco de embocadura de la capilla, que al abarcar todo el espacio entre los estribos hizo necesario demoler la zona baja del muro. Sin embargo, la parte existente no conserva el hueco de ventana antiguo que debió tener, a tenor de los existentes en los tramos aledaños, por lo que consideramos que sufrió también alguna reforma.

Si nos ocupamos de los elementos exteriores, existen en la zona de estudio tres arbotantes de dimensiones semejantes pero con una forma algo diversa (Fig. 12). Esta variación se debe a sus diversas fases constructivas, reformas y reparos. Los tres están formados por un esbelto arco de descarga y un ancho botarel acabado exteriormente en pináculo hacia el exterior del estribo. El arbotante $\mathrm{AB} 1$ fue rehecho tras la construcción de la torre, como ya hemos comentado (Fig. 12a). Al rehacer el arbotante se sustituyó el arco de descarga por piezas nuevas, reutilizando la fábrica aparejada sobre él. Posteriormente el pináculo sufrió numerosos daños por su cercanía a la torre que nunca fueron solucionadas; así pues actualmente sólo hay un amasijo de fábricas y trozos de piedra. Entre ellas observamos alguna pieza original cuyas molduras son distintas a las conservadas en los dos siguientes arbotantes, realizados por Diego de Riaño en 1530.

En el arbotante $A B 2$, los sillares sobre su arco de descarga están desnivelados respecto a las hiladas del botarel debido al descenso del punto de apoyo en el muro de la nave central, razón por la que está apeado y reforzado con elementos metálicos cuya fecha de fabricación hemos indicado en la relación cronológica (Fig. 12b). En la actualidad, este último apoyo es un simple adosamiento, mientras en el estado originario sería un empotramiento, como aún podemos apreciar en el siguiente arbotante, el AB3 (Fig. 12d). Las piezas se reajustan hasta la posición de equilibrio que el apuntalamiento consiguió detener, dejando a la vista la deformación.

Finalmente, el arbotante $\mathrm{AB} 3$ es el que mejor mantiene su configuración original, debido a la existencia de la capilla de San José levantada en el s. XVII, con una fábrica bien fundamentada, trabada y aparejada con el estribo (Fig. 12c). La forma de la sección del arco y la moldura superior coinciden con el anterior, siendo los dos coetáneos a la reforma realizada bajo la maestría de Diego de Riaño.
Todos estos arbotantes mantienen una gran horizontalidad en su parte superior que no acuerda con el punto de descarga de la bóveda de la nave principal, contradiciendo su original sentido estructural. Esta escasa inclinación dificultaba también la evacuación de aguas pluviales de la nave central a través de la habitual canal cerámica practicada sobre el estribo, por lo que fue cegada durante la reforma barroca y sustituida por unas gárgolas laterales al arbotante en el muro de la nave central que ejercían dicha función.

Entre estos elementos constructivos del templo gótico se eleva la capilla dedicada a la Virgen de la Antigua, un escueto espacio de apenas doce metros cuadrados formado por dos muros laterales que son los avances de los estribos antes descritos, un muro de fondo de piedra de $45 \mathrm{~cm}$ de espesor de dos hojas de sillares, una bóveda pétrea artesonada con casetones cuadrados y una gran portada enmarcada por un orden corintio sobre pilastras adosadas de escaso relieve y rematada por un completo friso y frontón. La portada de la capilla está labrada en piedra de mayor densidad y finura que las que componen el resto de la fábrica, permitiendo desarrollar una decoración más pormenorizada.

La composición interior de los cierres laterales de la capilla la conocemos a través de la extracción de testigos profundos realizados en esta campaña de estudios previos ${ }^{8}$. Se ha comprobado cómo los sillares exteriores del muro de fondo de la capilla se adosa a los estribos (Fig. 13). Es en este punto de unión donde su espesor se reduce de manera notable. La interior, sin embargo, queda trabada a los dos paramentos laterales, formados por estrechos sillares de piedra que, a su vez, trasdosan el estribo 2AI y labran el estribo $1 \mathrm{AI}$, junto a la torre.

La bóveda está ejecutada totalmente en piedra, con piezas de nervios y cruceros revirados formando un artesonado ortogonal de "moldes cuadrados» sobre los que se apoyan dos tablas de piedra por cada artesón (Fig. 14). La bóveda se apoya sobre el muro frontal y laterales mediante arcos formeros, aparejado con el arco de la embocadura tal como ya hemos indicado. Corresponde con bastante precisión al tipo de bóveda "capilla perlongada por cruceros" cuya montea queda recogida en el manuscrito de corte de piedra de Alonso de Vandelvira?. Los nervios y cruceros que forman la cuadrícula son «revirados», es decir, su

\footnotetext{
8 Estos datos corresponden a los trabajos realizados durante los meses de noviembre y diciembre de 2008 por la empresa Vorsevi. SL. recogidos en el informe I-ES-PT0350/08.

${ }^{9}$ Barbé-Coquelín (1977). Este trazado lo podemos encontrar en los folios 98v y 99r de esta edición facsímil.
} 


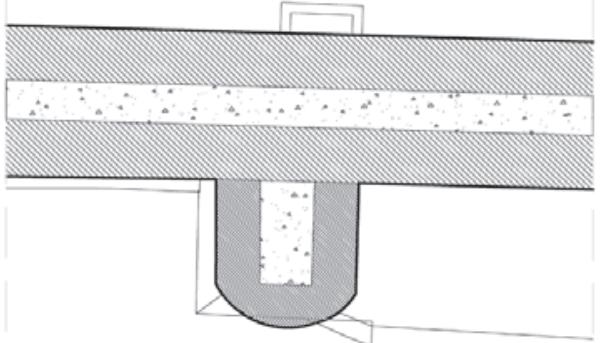

SECCIÓN $+8,00$
SILLARES DE PIEDRA CALIZAS. XV REFORMA ANTÓN RUIZ. 1506.

SILLARES DE PIEDRA CALIZA 1523-33 REFORMA DE DIEGO DE RIANNO.

SILLARES DE PIEDRA CALIZA 1535 CONSTRUCCIÓN CAPILLA MARTIN DE GAII

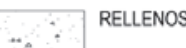

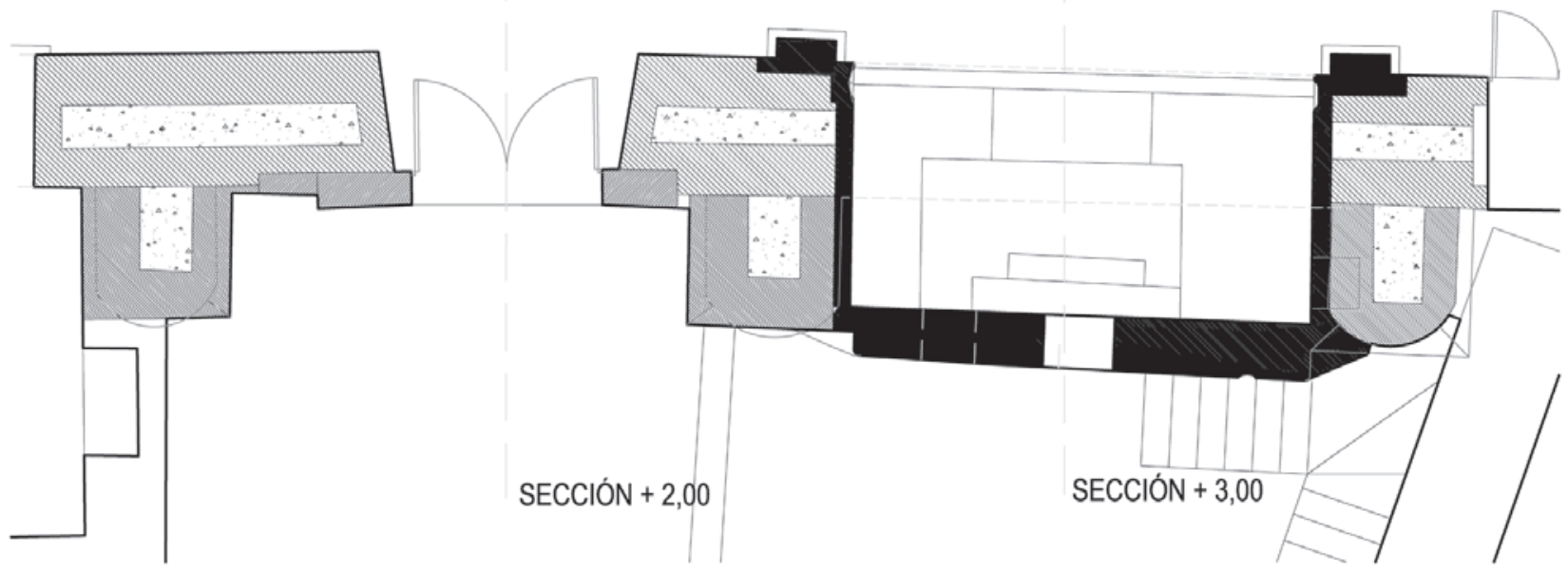
$10 \mathrm{~m}$

Fig. 13. Unidades constructivas obtenidas a partir de los ensayos. (Dibujo de los autores, 2008)
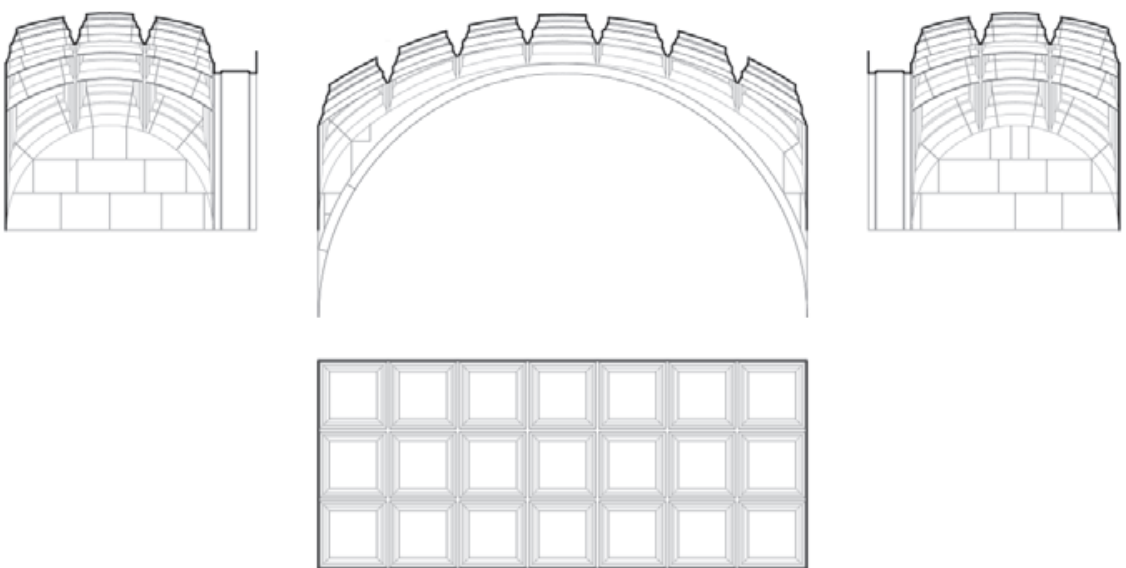

Fig. 14. Proyecciones ortogonales de la bóveda de la capilla de la Antigua sin deformaciones. (Dibujo de los autores, 2008) 


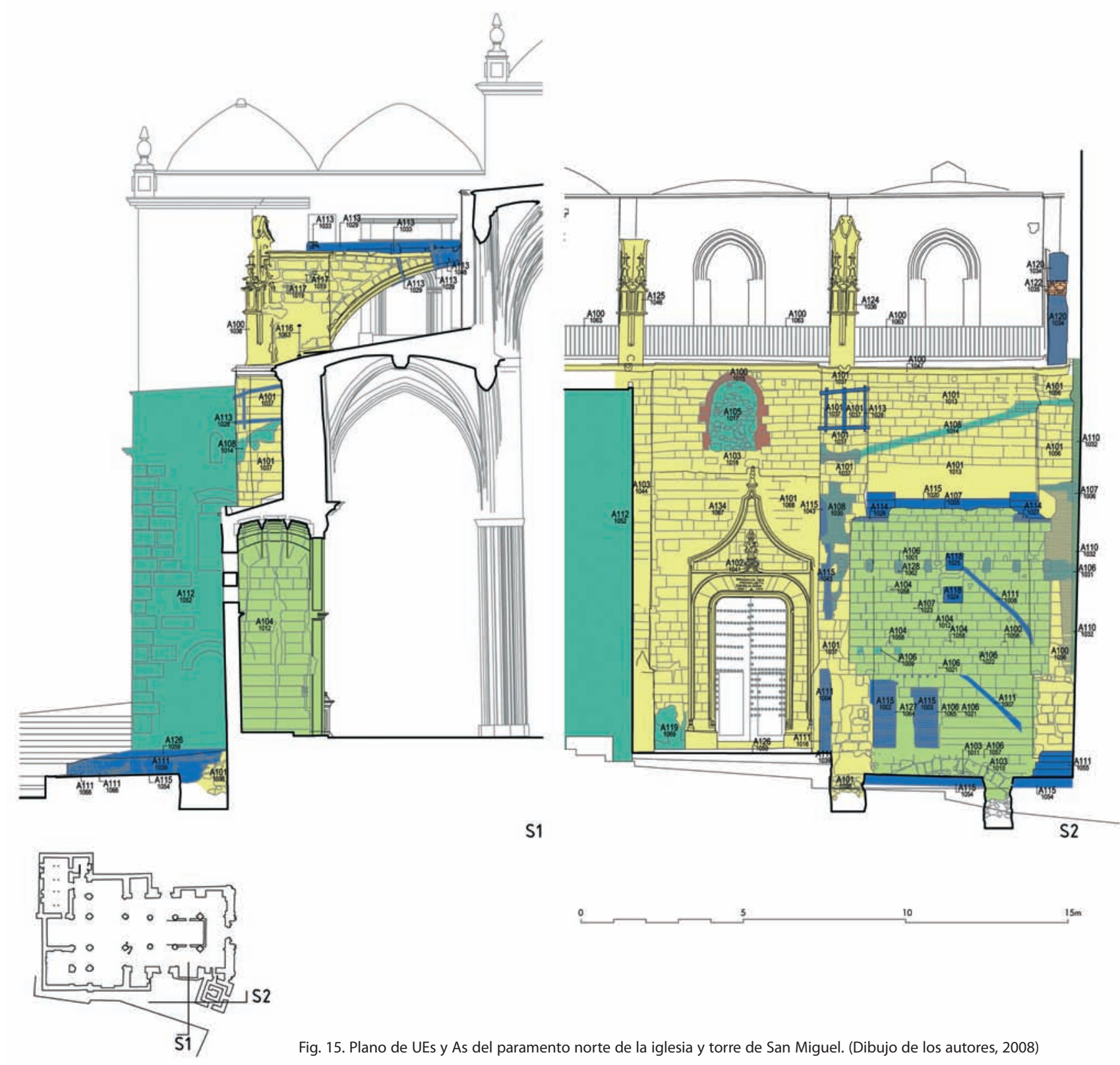

sección responde a un eje vertical que va deformando la sección de cada pieza ${ }^{10}$.

Como suele ser habitual en este tipo de bóvedas, está iluminada por un pequeño hueco situado en el muro frontal, cuyo aporte de luz contribuye a realzar el relieve del artesonado. En la actualidad está muy desfigurado y deteriorado por cegamientos de reformas posteriores y por quedar oculto tras el altar de madera barroco. En la actualidad

\footnotetext{
${ }_{10}$ Pinto $(2001,66)$. Este tipo de bóvedas es introducido en el arzobispado hispalense por Diego de Riaño, dejando magníficos ejemplos en el presbiterio y dependencias anexas de la Sacristía Mayor de la catedral hispalense, en la capilla de la Vela de la iglesia de Santa María de la Oliva en Lebrija, o en la sacristía de la iglesia parroquial de Aroche, en Huelva. Será Martín de Gaínza quien continúe esta tradición, primero como su aparejador y después como su sucesor en el cargo de maestro mayor del Arzobispado.
}

todo el conjunto está densamente apuntalado, pues el giro sufrido por el muro de fondo de la capilla (I12) hacia el exterior abrió la bóveda en horizontal unos $13 \mathrm{~cm}$, descalzando y descomprimiendo todos los nervios trasversales.

Para finalizar la descripción del estado actual del conjunto, observamos sobre el paramento exterior de la capilla, el aledaño este de la torre y el suelo entre ambas, restos de una antigua edificación anexa que ocupaba aquel rincón. Los restos de mayor volumen son los del suelo, pues conservan el arranque de los muros demolidos y de su cimentación. Para documentar esta casa ha sido fundamental la realización de la lectura estratigráfica de sus paramentos y la existencia de algunas imágenes de la edificación hoy desaparecida (Fig. 8). 

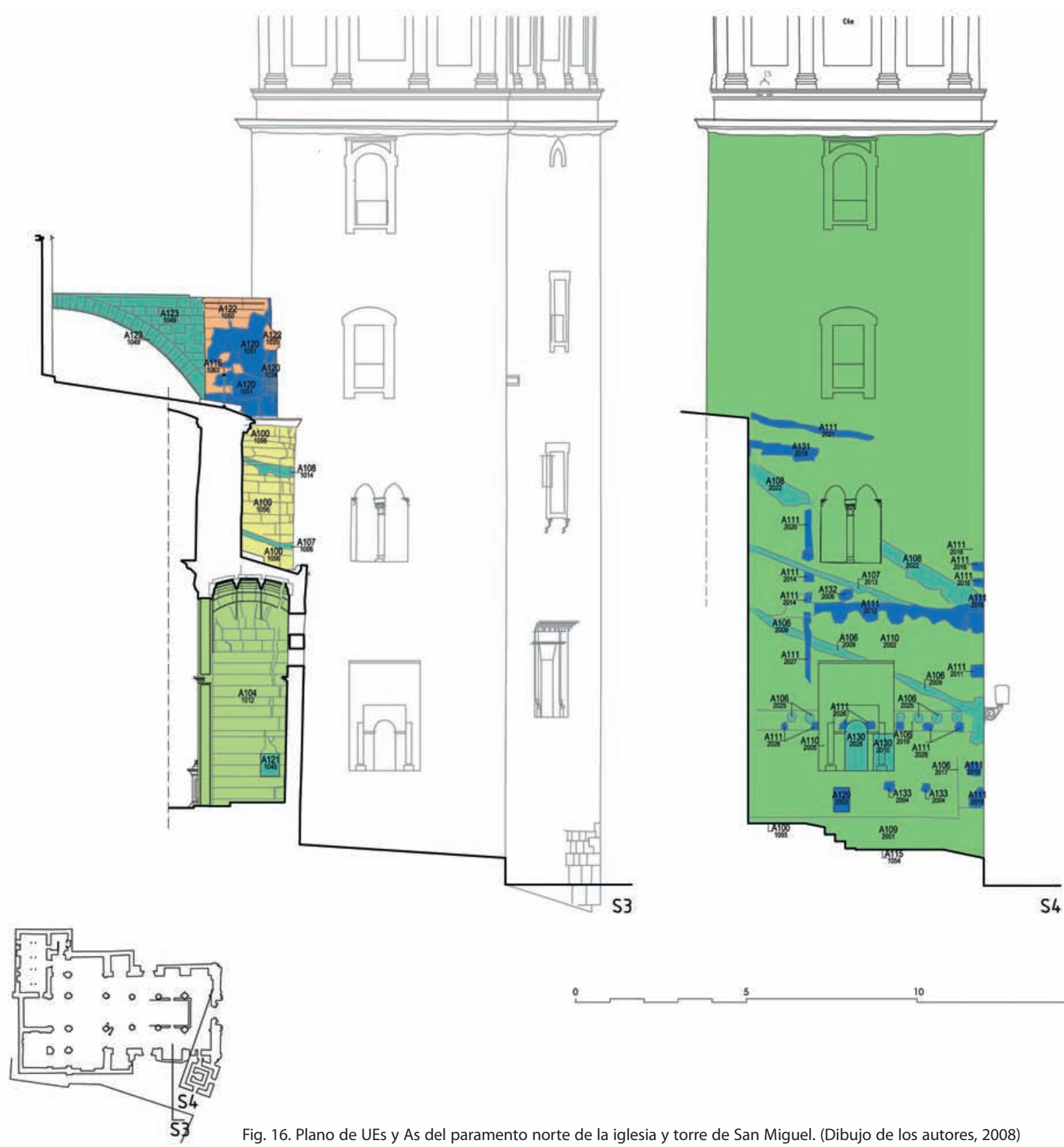

Fig. 16. Plano de UEs y As del paramento norte de la iglesia y torre de San Miguel. (Dibujo de los autores, 2008)

La demolición de este cuerpo anexo llevada a cabo en 1970 dejó importantes roturas en los encastres de los muros de la casa con la torre y los estribos, que fueron reparados con fábrica de ladrillo macizo que han soportado mal el paso del tiempo. En estos puntos se acumulan las mayores pérdidas de material lo cual ha generado una debilitación de estos elementos estructurales junto a otras causas como el abandono, la humedad y la concentración de vegetación, por ello fue necesario realizar un apuntalamiento de urgencia en 1998. A su vez, este apuntalamiento modificó el terreno exterior de la capilla, introduciendo tres zapatas aisladas que sustentan los correspondientes pies derechos metálicos, y sobre ellas una solera de $30 \mathrm{~cm}$ que maciza los tirantes horizontales que unen los tornapuntas. Las catas arqueológicas realizadas en los trabajos previos han detectado estas estructuras, que profundizan hasta $150 \mathrm{~cm}$ bajo el nivel de la solería del templo.

Con estos precedentes, la lectura estratigráfica se centró en los paramentos correspondientes a la capilla, nave lateral norte entre la torre y la capilla de San José y el paramento aledaño de la torre (Figs. 15, 16 y 17). A partir de esta lectura estratigráfica, de las noticias históricas, los documentos inventariados, los sondeos realizados, el análisis arquitectónico y los dibujos, llegamos a pautar los períodos temporales que exponemos a continuación. 


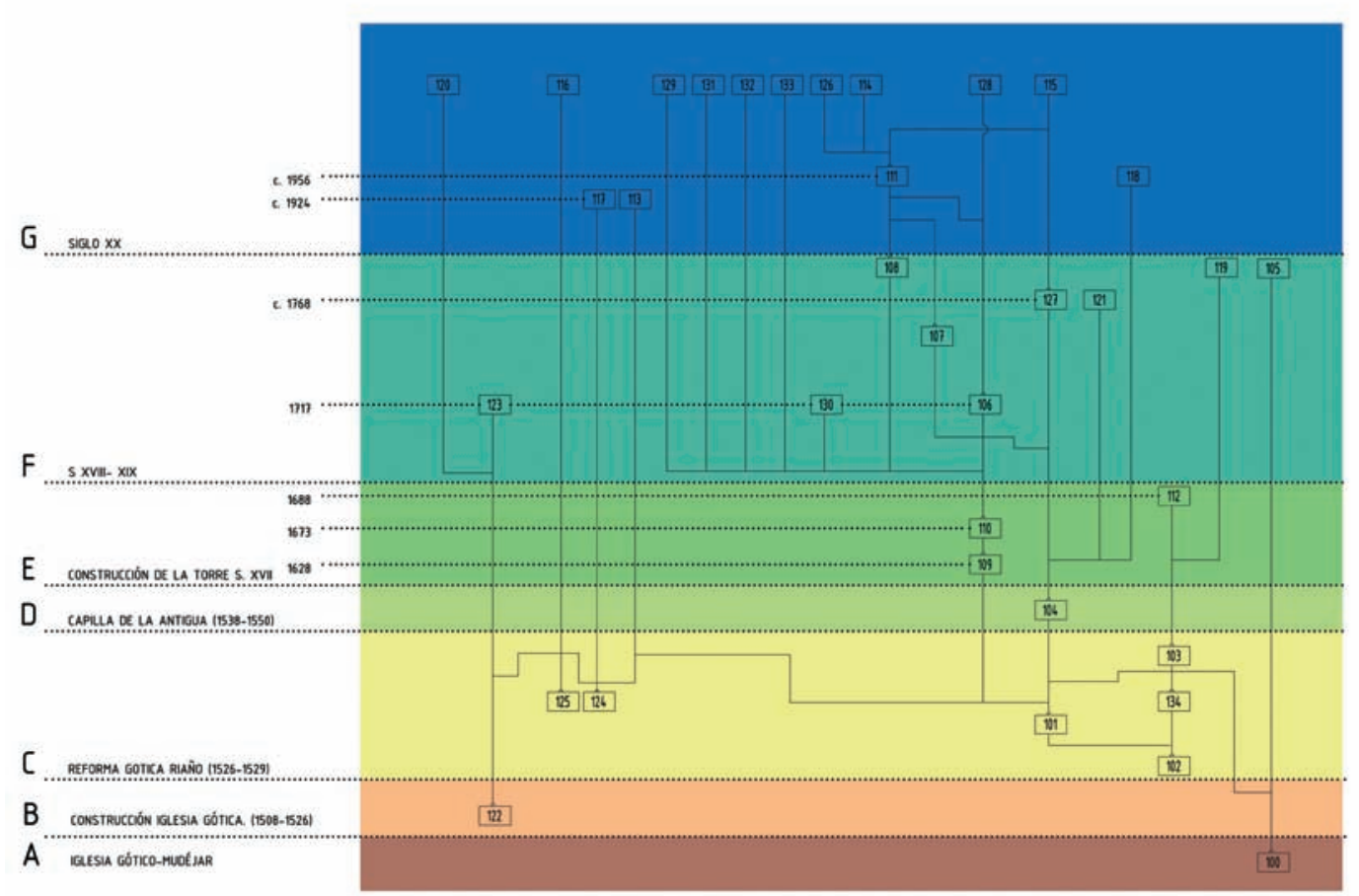

Fig. 17. Matriz de actividades del paramento norte de la iglesia y torre de San Miguel

\section{PERIODO 0: Estructuras Previas al templo}

A través de las excavaciones arqueológicas se han verificado restos procedentes de asentamientos de época romana en los planos más profundos; sin embargo, el reducido alcance de las mismas no permite precisar adecuadamente sus características. Sobre estos se ha localizado un asentamiento bajomedieval que corresponde a las primeras ocupaciones junto a la antigua fortificación, primera zona de expansión de la ciudad, también con escasos restos y datos sobre el modo de ocupación. Estos hallazgos constatan la necesidad de contar con un conocimiento previo del propio contexto urbano para una mejor comprensión del edificio, del que por ahora carecemos. Sólo es posible asegurar, por ahora, la inestabilidad de la estructura geotécnica del terreno en esta zona, tanto por la presencia de yesos como de numerosas remociones debidas a enterramientos y construcciones difíciles de documentar.

\section{PERIODO A: Iglesia gótico-mudéjar s. Xv}

A estos primeros e imprecisos asentamientos le sucede la edificación de un primer templo con presbiterio orientado al este, del que formaba parte el muro A, como paramento lateral y exterior norte. Este muro no tenía estribos, y en su exterior, en la zona hoy ocupada por la calle Siete Revueltas, existía un pequeño cementerio del que se han localizado numerosos restos en las dos excavaciones puntuales. Este primer edificio gótico-mudéjar quedó parcialmente arruinado tras el terremoto de 1504, quedando en pie algunos de los muros de la caja del edificio, que fueron reutilizados por las reformas posteriores. De esta primitiva edificación, tan sólo es visible en la actualidad la ventana de la fachada norte, situada sobre la portada (A100; UE 1015), que por tipología situamos en un momento intermedio entre esta época y la primera reforma gótica. La cara exterior del muro donde se abre esta ventana quedó reformada profundamente en un momento posterior. También se observan restos de estas estructuras primitivas en el muro opuesto, con el mismo tipo de fábricas y restos de ventanas, lo que ha llevado a varios investigadores a afirmar que la iglesia mantuvo la anchura de la primera, reajustándose interiormente.

La reutilización de estas estructuras a veces de forma muy fragmentaria, ha dejado ocultas discontinuidades constructivas que están generando patologías, sobre todo filtraciones, asientos diferenciales y distinto comportamiento ante los agentes atmosféricos. La localización de estas discontinuidades y la delimitación rigurosa de los fragmentos conservados es esencial, como ya hemos indicado, tanto para determinar la cronología del templo como para comprender el origen de las complejas deformaciones del conjunto.

\section{PERIODO B: Construcción iglesia gótica (1508-1526)}

Sin embargo, será la reforma gótica del templo, abovedando las naves laterales y el primer tramo de la nave central, 
la que produzca un mayor efecto transformador del edificio, y por tanto un mayor número de uniones entre fábricas de distinta época. Al elevar el cuerpo central de la iglesia fueron necesarios arbotantes y estribos cuyo diseño se ha comprobado deficiente. La posterioridad de estos elementos respecto al muro A, se comprueba en la discontinuidad de sus fábricas y en la rotura que sus cimientos produjeron en los enterramientos antiguos. La escasa diferencia de altura entre la nave central y las laterales (en parte herencia de la experiencia de la catedral hispalense) obliga a que los arbotantes sean muy horizontales y acometan en puntos de descarga de la bóveda inapropiados, lo que a la larga ha producido giros importantes en los pilares.

De este periodo constructivo, dirigido por el maestro Antón Ruiz, se conserva el primer pináculo y la pila del estribo saliente del arbotante junto a la torre (A122; UE 1035,1050 ), construido para recibir los empujes transmitidos por la bóveda del primer tramo de la nave central. La asignación es una vez más tipológica, es decir, se analizan los elementos arquitectónicos existentes (pilares, bóvedas, ventanas, molduras, etc.) y se comparan con los modelos del llamado gótico catedralicio ${ }^{11}$ (Fernández Naranjo 2007).

\section{PERIODO C: Reforma gótica. Diego de Riaño (1526-1529)}

En este período se lleva a cabo la continuación de la reforma antes expuesta, ahora bajo la maestría de Riaño, que construyó el resto de las bóvedas laterales de los tramos segundo y tercero, y reforzó los muros existentes. Se realizan en este momento el segundo y tercer arbotante (A124; UE 1036 y A125; UE 1046 respectivamente), una vez levantados los distintos paños de fábrica de cantería y los estribos correspondientes (A101; UEs 1013, 1037, 1038, 1056. A134; UE 1067. A103; 1018, 1044). En este proceso podemos distinguir diferentes fases constructivas, así se puede observar cómo el tercer estribo (UE 1044) es posterior a la zona de fábrica de cantería junto a la portada (UE 1067), mientras que es coetáneo a la fábrica de la parte superior (UE 1018) (Fig. 18). También se detecta la falta de traba entre el segundo estribo y la parte superior del muro de la iglesia, sobre la portada.

Esta segunda reforma se produce entre 1523 y 1533 , años en los que Diego de Riaño está a cargo de las obras,

\footnotetext{
${ }^{11}$ A estos estudios habría que añadir el de las marcas criptográficas (marcas de cantero, de procesos y montajes de obras, etc.) aún escasamente registradas en el edificio.
}

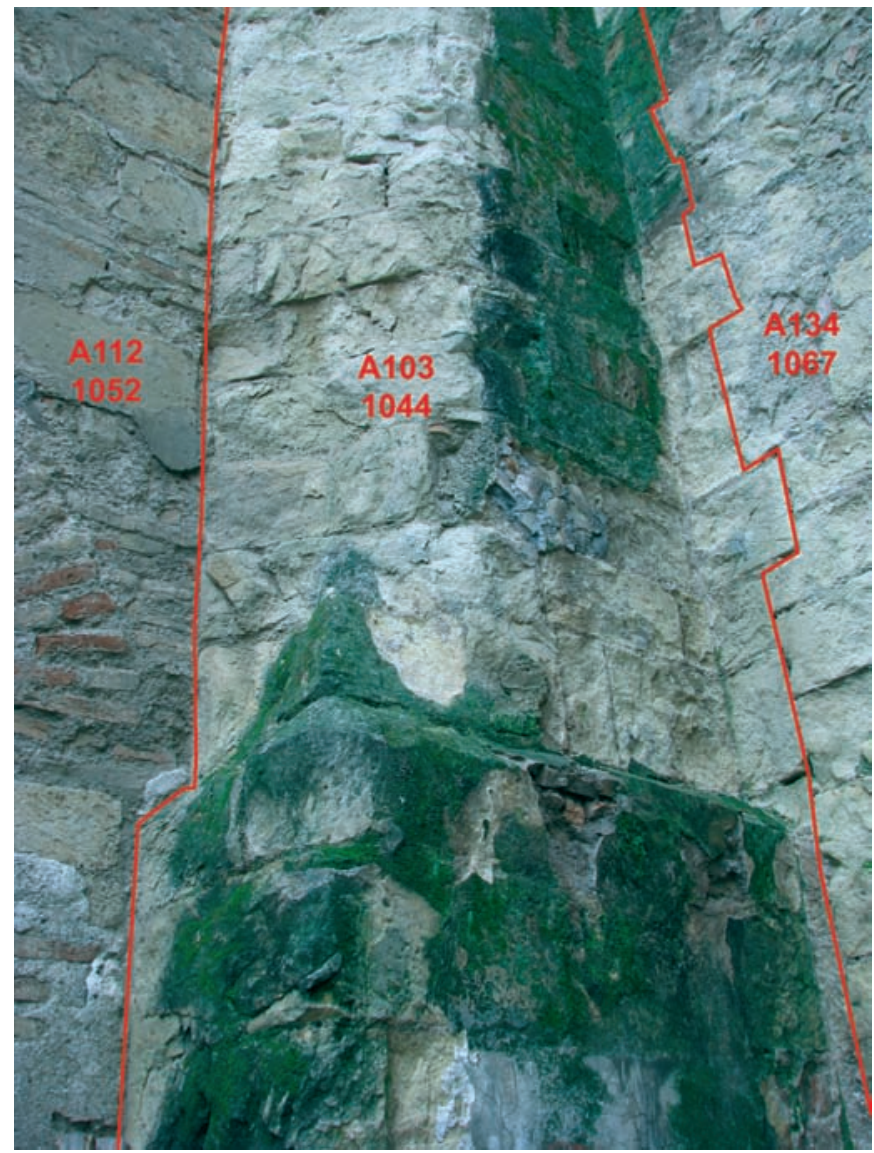

Fig. 18. Identificación de UEs del estribo A3

primero como aparejador $y$, tras un pequeño margen temporal sin actividad, como maestro mayor del Arzobispado. La reforma pretende aportar monumentalidad a la fachada norte del edificio mediante una composición muy elaborada (Fig. 19). Debemos considerar que en este momento no existía la torre y la la fachada se configuró para un espacio más amplio, actualmente desaparecido. Este modo de componer, tratando escultóricamente los estribos, lo podemos observar en otras obras de este maestro: la reforma de la fachada lateral de la iglesia Prioral del Puerto de Santa María, en las dependencias parroquiales de Santa María de Arcos de la Frontera, y en el alzado de las estancias capitulares de la propia catedral hispalense.

\section{PERIODO D: Construcción de la capilla de la Antigua (1538-1550)}

La construcción de la capilla en el segundo tercio del s. XVI se produce a la vez que se inicia el cuarto tramo de la nave. Ambas fueron dirigidas por el maestro Martín de Gaínza, antiguo aparejador de Diego de Riaño, que retoma sus obras tras su fallecimiento. Con la obra de la capilla se abandona las intenciones compositivas del periodo ante- 

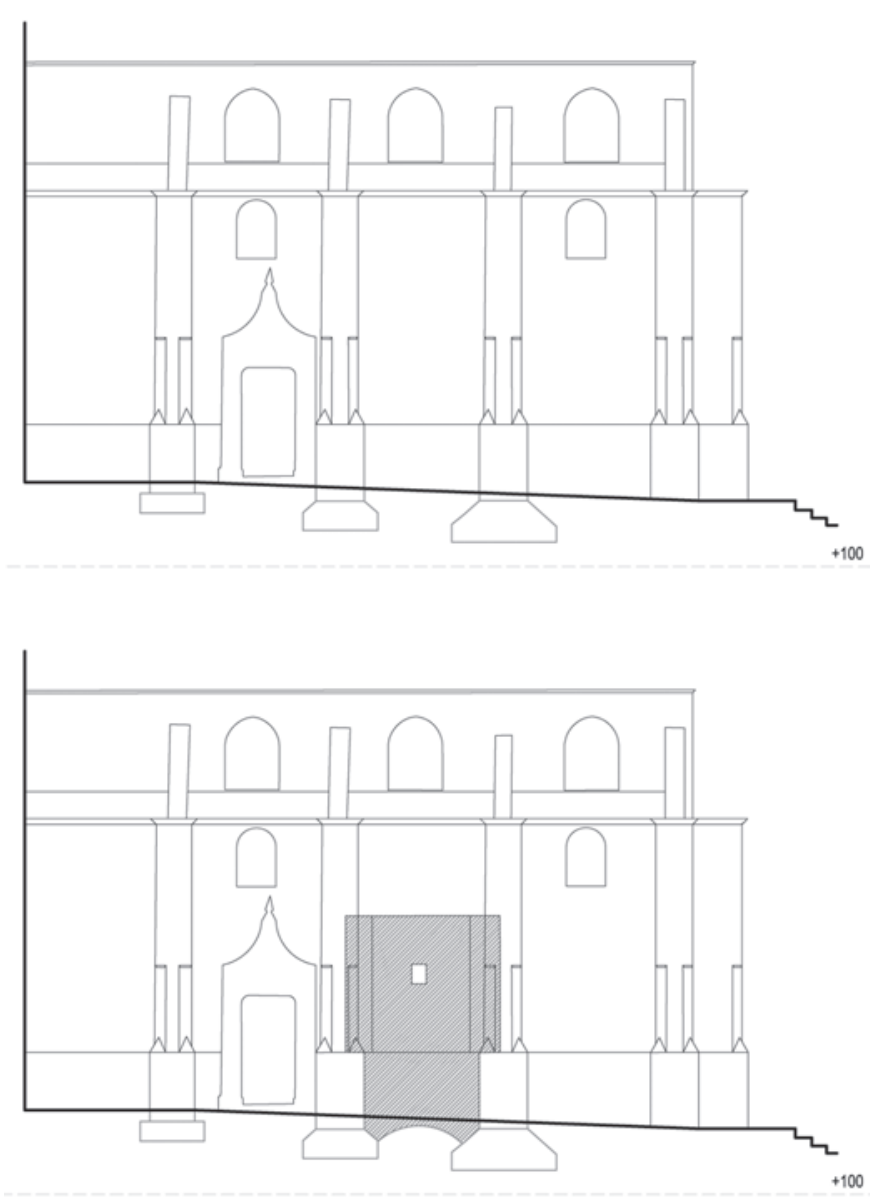

0

Fig. 19. Hipótesis de estado de la fachada norte antes y después de la construcción de la capilla. 1535. (Dibujo de los autores, 2008)

rior, al insertar un volumen ajeno a los elementos previstos por el maestro de Riaño.

La capilla de la familia de los Auñones o de la Virgen de la Antigua (A104; UEs 1010, 1011, 1012, 1058), se realiza abriendo un gran hueco hacia las naves de la iglesia y ocupando un espacio situado entre dos estribos. La cimentación se resuelve mediante un arco de descarga (UE 1010) que apoya en la cimentación de los estribos. La relación de posterioridad de la capilla respecto a la fase anterior se refleja, por un lado, en el adosamiento por encastre en la parte inferior del muro, que coincide con la parte cuadrangular de los estribos; y por otro, en el adosamiento simple, sin traba, de la parte superior. Se aprecian además varios mechinales propios del proceso constructivo (UE 1058).

Por otra parte, los elementos pétreos de esta portada se diferencian con claridad de las fábricas vecinas en color y textura, pero sobre todo porque la traba no sigue las mismas hiladas del muro. Al observar el despiece del arco de

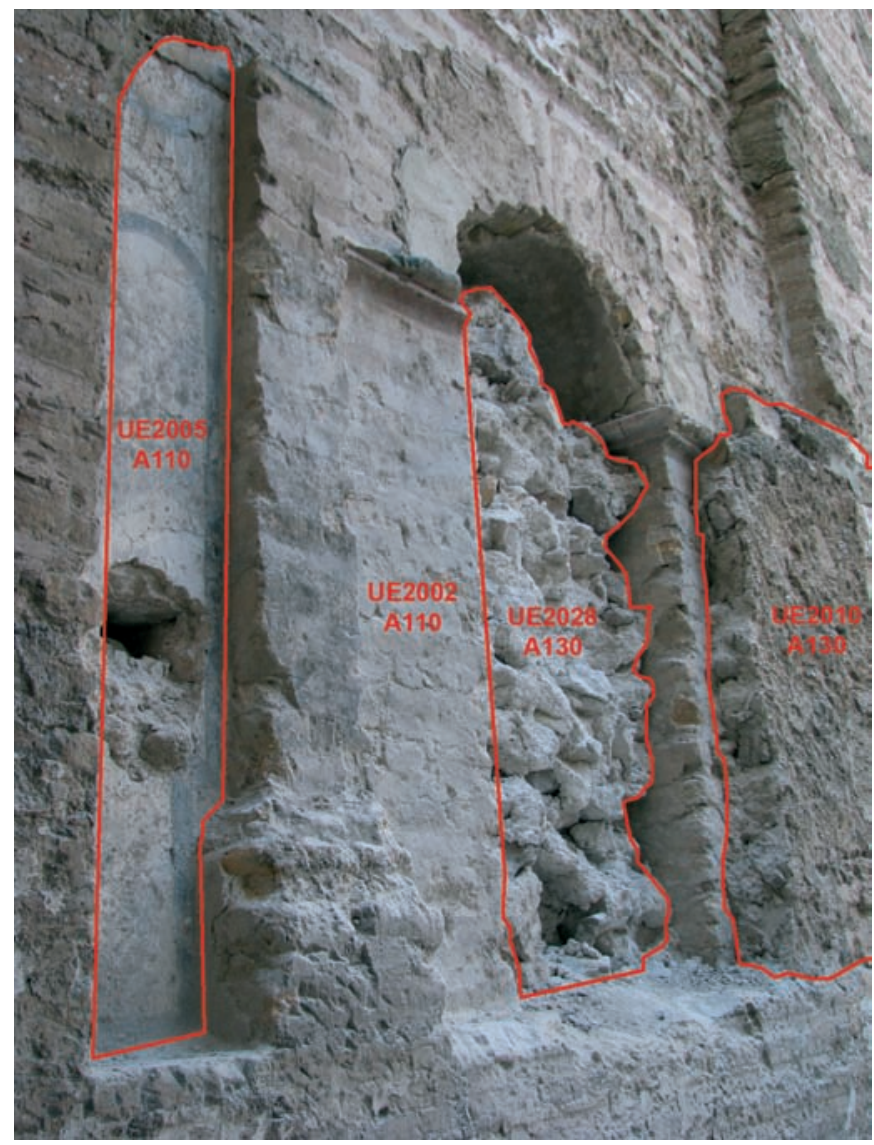

Fig. 20. Identificación de UEs del estribo A1

esta portada descubrimos su contemporaneidad con la bóveda, pues están trabados entre sí, compartiendo decoración y despieces de cantería. Podemos decir entonces, apoyándonos en el levantamiento gráfico y en los sondeos practicados, que un tercio de la bóveda está sirviendo de arco de descarga del muro, formando una especie de capialzado. De hecho, la rotura más importante de la bóveda aparece en los otros dos tercios, manteniéndose comprimido y en buen estado el tercio que está bajo el muro.

\section{PERIODO E: Construcción de la torre y capilla de}

\section{San José (s. XVII)}

En la torre se aprecian dos partes claramente diferenciadas: la base de la misma (A109; UE 2001) realizada en fábrica de cantería, que por la documentación histórica podemos datar en 1628, y por otro los muros (A110; UE 1032, 2002) realizados en fábrica de ladrillo, datados a su vez en fechas cercanas a 1673 .

Podemos situar en este momento los restos de enlucido con decoración geométrica (A110; UE 2005) en el hueco inferior de la torre (Fig. 20). Además, en 1688 se construyó la capilla de San José (A112; UE 1052), cuyos muros se adosan también al estribo gótico. 
El encuentro de la torre con la fábrica de la iglesia refleja esta relación de posterioridad por adosamiento simple (Fig. 21). El pequeño espacio de forma trapezoidal resultante entre la torre y la pared de la iglesia, ha sido desalojado de tabiques y añadidos contemporáneos que lo habilitaban como improvisado trastero, dejando a la vista huellas que debemos leer aún, cuando podamos contar con instalaciones y medios adecuados no disponibles durante estos trabajos previos. Queda intacta una ventana tapiada de la iglesia inicial y la configuración del estribo entre el primer y segundo tramo, cuya geometría, molduras y fábrica están aún intactas, así como numerosas marcas que se intuyen en la oscuridad de la estancia.

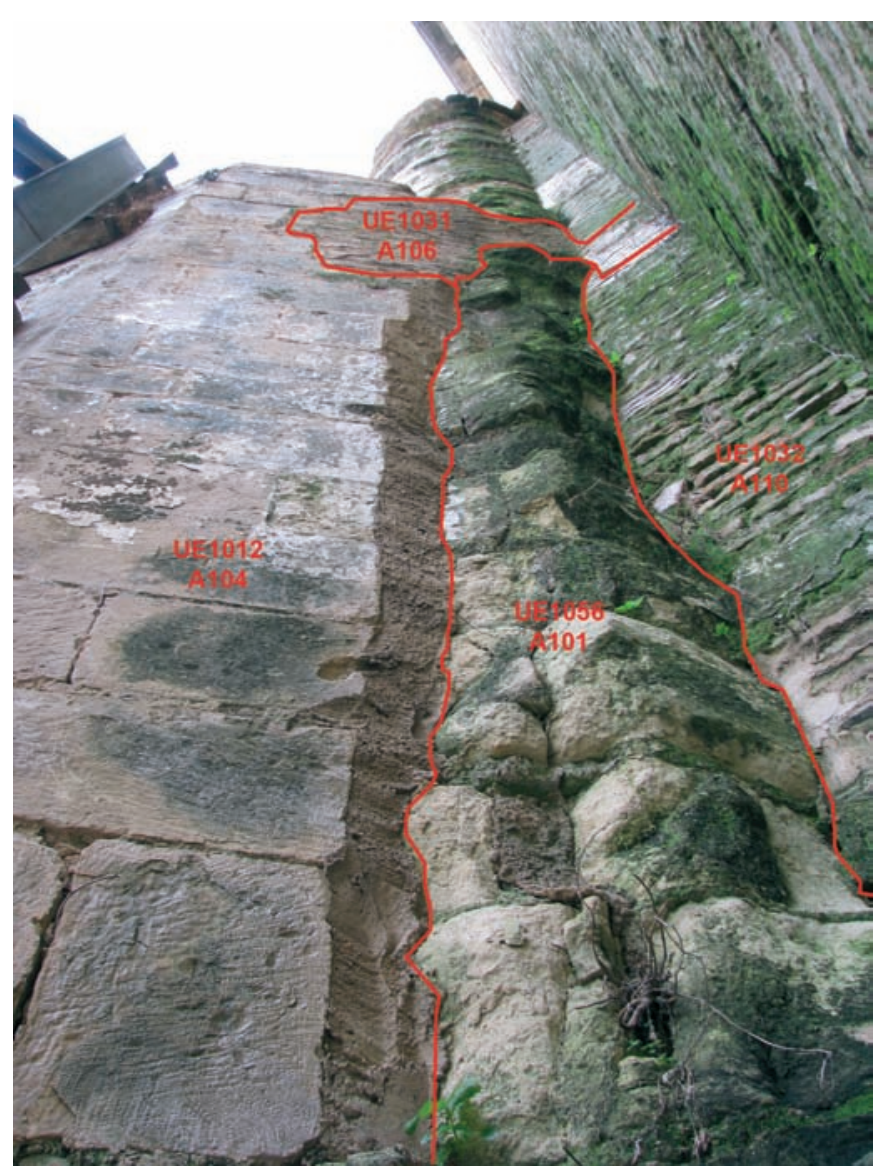

Fig. 21. Identificación de UEs del hueco descubierto en la parte baja del paramento de la torre junto a la capilla

Si a estas obras añadimos la reforma barroca de las fachadas oeste y sur formando un conjunto compositivo, la norte adquiere un carácter residual y secundario, casi de trasera del edificio. La torre apuesta claramente por una nueva configuración urbana al quedar alineada con la calle San Miguel, que desciende hacia el ayuntamiento, asumiendo el papel de hito urbano lejano.

\section{PERIODO F: Siglo XVIII y XIX}

La última fase constructiva importante en relación a la capilla queda determinada por la construcción de una edificación auxiliar en el espacio existente entre ésta, la torre y la calle Siete Revueltas. Las sucesivas transformaciones fueron marcando una serie de ampliaciones en altura que han dejado sucesivas huellas en los muros de la torre y la capilla, a través de las cuales podemos distinguir tres fases diferentes que enunciamos como casa 1,2 y 3 , siendo siempre reformas sobre el mismo edificio:

- Construcción de la casa 1 (A106; UEs 1001, 1009, 1021, 1022, 1031, 1057, 1065, 2009, 2017, 2019, 2025).

Tenemos noticia de que en 1717 se construye en este lugar una casa para los curas semaneros, comunicada con la iglesia a través de la capilla Virgen de la Antigua. Se trataría de una edificación con una cubierta de madera inclinada que se apoyaría en la capilla, de la cual podemos apreciar los mechinales realizados en el muro (UE 1001), y la huella lateral de dicha cubierta en el muro de la torre (UE 2009; Fig. 22). Existen también huellas de los revestimientos realizados en este momento mediante encalado directos sobre la fábrica, que se interrumpen linealmente en los extremos, indicando la posición de los muros de carga (UEs 1021, 2017). Se observa también las huellas de los mechinales más pequeños (UEs 1009, 2025) de un forjado intermedio (UE 1022) que servía como falso techo de las estancias bajas y como suelo de un sobrado alto para almacenaje o cámara. En este momentos se abriría uno de los huecos de comunicación con la capilla (UE 1065) y se ciega el hueco inferior de la torre (A130, UE 2010, 2028) que quedaba ahora en el interior de la casa. El nivel de la solería queda marcado por la huella del revestimiento sobre el muro de la capilla (UE 1057).

- Construcción de la casa 2 (A107; UEs 1005, 1006, 2013).

Se produce una ampliación de la edificación anterior aumentando la altura de la cubierta inclinada para añadir una segunda planta habitable donde antes sólo existía una cámara. Esta estancia tendría un nuevo falso techo y un sobrado, produciendo una nueva cubierta inclinada (UEs 1006, 2013) que al elevarse apoyaría en la parte superior del muro de la capilla. Situamos en este momento la rotura de la parte superior del muro (UE 1005), aunque también pudo producirse al demoler dicha cubierta posteriormente. 


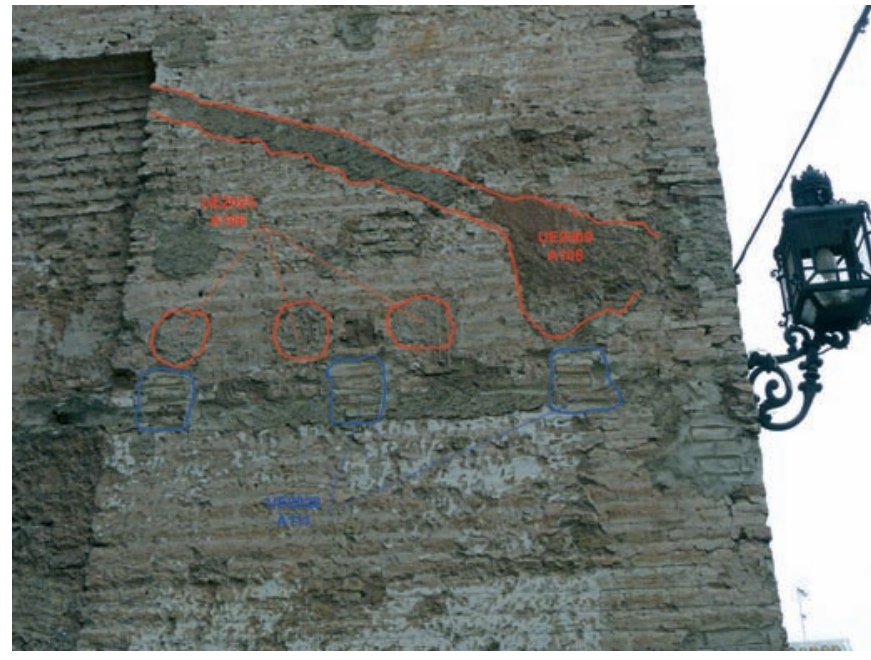

Fig. 22. Identificación de UEs del paramento de la torre junto a la capilla

- Construcción de la casa 3 (A108; UEs 1014, 1030, 2022).

Se produce una nueva modificación de la pendiente de la cubierta (UEs 1014, 2022) y un recrecido de los muros (UE 1030). El objetivo de esta operación pudo haber sido el uso como planta habitable del espacio que antes era una simple cámara, llegando así al nivel de coronación de las naves laterales. Aún se conserva alguna imagen fotográfica de esta cubierta (Fig. 7).

Además de la edificación mencionada podemos situar en este período otra serie de actuaciones como son:

- Reconstrucción del arco del primer arbotante (A123; UE 1049). Esta operación puede estar vinculada con la reforma efectuada en torno al año 1717 de la fachada sur y oeste del templo, que trajo consigo la reconstrucción de todos los arbotantes de este flanco, semejantes constructivamente al que tratamos.

- La construcción del retablo, en 1768, supuso el cegado del hueco anterior que servía de comunicación entre la casa y la capilla, y la apertura de un nuevo hueco junto a dicho retablo (A127; UE 1064). Quizás esta reforma de la distribución interior de los enseres de la capilla pudo suponer también la apertura de una pequeña hornacina en el muro lateral de la misma (A121; UE 1045) para uso de enseres litúrgicos, pues el resto de las paredes estaba ocupado por altares y la puerta mencionada.

- El revestimiento del muro de cantería con un mortero y enlucido continuo esgrafiado simulando el despiece de sillería (A119; UE 1069). Tal vez podríamos situar en este periodo el cegado de la ventana sobre la portada principal (A105, 1017), aunque no existen pruebas suficientes para ello.

\section{PERIODO G: Siglo $x x$}

Se realiza el refuerzo del segundo arbotante (A113; UEs $1028,1029,1033,1048)$, acción que podemos datar en torno a 1924 por los documentos históricos. Consistió en la colocación de unos refuerzos metálicos y la sustitución de las dovelas en el encuentro del arco con el muro de la nave principal, así como la colocación de unas pletinas metálicas en la parte superior del estribo correspondiente (A117, UE 1019).

A mediados de siglo se realiza la construcción de la casa del coadjutor (A111; UEs 1004, 1007, 1008, 1016, 1023, 1039, 1055, 1066, 2011, 2012, 2014, 2015, 2016, 2020, 2021, 2026, 2027). En 1956, en el espacio ocupado por la antigua edificación junto a la torre y a la capilla, se construye una vivienda para el coadjutor de la iglesia (Fig. 8). Este edificio tenía acceso por la calle de las Siete Revueltas, por lo que el nivel de solería de la planta baja se situó por debajo del existente hasta entonces. En el muro de la capilla se aprecia la huella de las dos escaleras (UEs $1007,1008,1055)$, así como de los forjados que se apoyaban en los muros de la torre (UE 2012, 2026). Los muros de esta nueva edificación estaban construidos con fábrica de ladrillo macizo de un pie del que quedan restos junto al terreno (UE 1004, 1039) y huellas del encastre de éstos en la fábrica de la capilla y de la torre (UE 1016, 2015, 2016). Podríamos situar por esta época la apertura de uno de los huecos en la parte superior del muro de la capilla (A118; UE 1025) para el apoyo de una viga de carga que queda reflejada en los planos del proyecto. Aunque pensamos que el origen del hueco inferior a éste (A118; UE 1024) pudiera haberse realizado junto con la construcción de la capilla, es posible que esta intervención motivara su deterioro o pérdida de piezas originales que le confieren el actual aspecto de ruina.

Tras la demolición de la casa, en las restauraciones llevadas a cabo en la década de los 70 de este siglo, se han sucedido años de precariedad estructural y degradación, en las que han quedado expuestas las heridas producidas en la fábrica durante todo este complejo proceso evolutivo. La grave inestabilidad que se observaba hicieron necesaria la colocación de un apuntalamiento (que intencionadamente no hemos introducido en la lectura paramental para no hacerla más compleja) así como el retacado de mechinales y huellas existentes. En este sentido, podemos enmarcar una serie de actividades (A131; UE 2018. A132; UE 2006. 

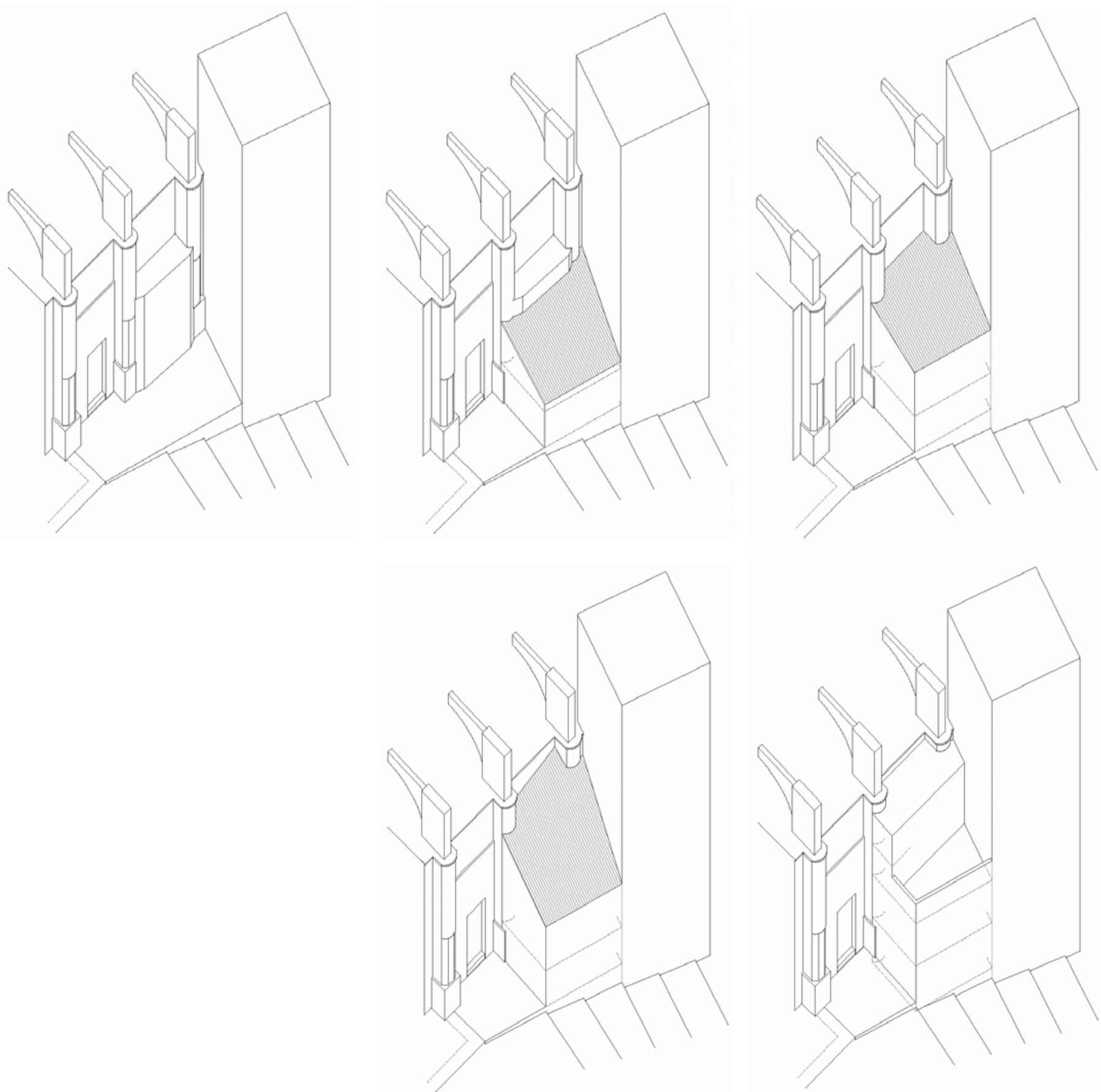

Fig. 23. Hipótesis de evolución histórica de la desaparecida construcción anexa a la capilla de la Antigua: a) Construcción de la capilla (1538); b) Casa 1 (1717); c) Casa 2 (?); d) Casa 3; (?); e) Casa para el coadjutor (1956). (Dibujo de los autores, 2008)

A133; UE 2004. A114; UEs 1026, 1027. A128; UEs 1062. A115; UE 1002, 1003, 1020, 1043, 1054).

Existe además otra serie de acciones coetáneas como la colocación de una barandilla metálica en la azotea de la nave lateral de la iglesia (A116; UE 1063), las reparaciones efectuadas en el primer pináculo (A120; UEs 1034, 1051), el acerado de baldosas hidráulicas frente a la entrada de la iglesia (A126; UE 1059) o la colocación de un contador eléctrico (A129; UE 2003).
En resumen, el proceso de transformaciones que concluye con la destrucción de estas dependencias nos muestran un progresivo aprovechamiento del inmueble a costa de la estructura de la capilla, que quedó totalmente oculta, transformó radicalmente el espacio existente y provocó un descalce de la cimentación, lo que sumado a los efectos anteriormente descritos han concluido en su ruina, tal como resumimos en los esquemas gráficos adjuntos (Fig. 23). 


\section{CONCLUSIONES GENERALES}

A modo de conclusión, proponemos algunas reflexiones en torno a las etapas y circunstancias de este estudio:

- Ante las perdidas sufridas en el devenir histórico de este edificio, era urgente registrar y documentar sus huellas con el mayor rigor y con los enfoques disciplinares más amplios, e incorporarlas como parte de la propia esencia del edificio.

- Los datos obtenidos a partir de los trabajos realizados nos han permitido reconstruir no sólo las transformaciones sufridas por el edificio, sino el propio origen de su grave estado estructural. Conocemos ahora cómo hemos llegado a la penosa realidad actual, suma de la propia precariedad de la construcción, de las desacertadas reformas coetáneas y, sobre todo, de la decisión final de aplicar un criterio de restauración basado en «demoliciones selectivas», de tristes consecuencias para nuestro patrimonio. Es quizás este último el síntoma más perceptible de un modo de pensar el monumento como imagen recreada de una época, evitando el mestizaje y la compleja y difusa realidad que forma parte de su propia esencia patrimonial.

- Cada uno de los resultados de estos trabajos previos debe verificarse con los datos que puedan obtenerse durante la intervención, pues ésta constituye un momento especial e irrepetible en la propia historia del edificio. En ocasiones, dichos datos son tan vulnerables y efímeros como necesarios para su comprensión. Podríamos en esto realizar un paralelo con la actividad arqueológica tradicional en el subsuelo, donde muchos elementos desaparecen en el propio proceso de investigación, requiriendo de un registro exhaustivo. Por lo tanto, el método seguido pretende que los trabajos no se concluyan como compartimientos estancos dentro de la investigación global del edificio.

- En lo que respecta al propio proyecto arquitectónico que sigue a estos trabajos previos, éste intenta responder a cada uno de los problemas planteados aquí. Quiere esto decir que la fase de realización de los trabajos previos es el momento de las preguntas, de llamar la atención en aquellos aspectos que se han de considerar; de definir los valores del propio edificio como objeto arquitectónico y como patrimonio. Estas valoraciones exigen estrategias y métodos precisos, que a la vez sean lo más racionales y científicos posibles, sin olvidar la componente interpretativa siempre presente.
- La respuesta del proyecto parte de estas premisas, planteando soluciones que dejen abiertas futuras interpretaciones a partir de datos que ahora quizás no llegamos a valorar en toda su dimensión. El caso que nos ocupa es quizás excesivamente concreto para establecer un juicio más genérico, pues no trata de rehabilitaciones, ni cambios de uso, ni reformas de sus volúmenes, sino de tratamientos para evitar, por un lado, el colapso de su esencia material y, por otro, la pérdida de sus valores.

- El proyecto planteado intenta devolver al edificio su consideración como tal, más allá del valor actual de resto fragmentado y roto. No se trata de recomponer nada más allá de lo existente, sino de revisar el modo aleatorio y confuso en que se presentan los acontecimientos. Como prioridad está la capilla, por otro la fachada norte del templo y por otro las huellas que han quedado expuestas en sus muros de forma accidental y que ahora comprendemos. A partir de lo expuesto, planteamos que la capilla, el muro norte y los estribos son tres piezas que deben entenderse como principales. Sus atributos de figura, tamaño, textura deben ser prioritarios en su visualización. Y sobre éstos, el conjunto de huellas que expresan sus circunstancias particulares, su historia, que deben entenderse como elementos de fondo, minimizando su presencia sin llegar a perderlos, a favor de los elementos principales. El proyecto, como interpretación de estos valores, admitirá todos los matices que seamos capaces de aportar en el propio proceso de la obra con los materiales y tratamientos previstos.

\section{Bibliografía}

Barbé-Coquelin de Lisle, G. 1977, El Tratado de Arquitectura de Alonso de Vandelvira. Albacete, t. II (facsímil).

Fernández Naranjo, J. A. 2004, La iglesia de San Miguel arcángel de Morón de la Frontera. Sintesis de arquitecturas. Tesis doctoral. Universidad de Sevilla.

Fernández Naranjo, J. A. 2007, Fascicvlvs, Simposium Internacional sobre la catedral de Sevilla en el contexto del gótico final, Sevilla, t. II, 307-323.

Manzano Martos, R. 1979, Proyecto de restauración del templo parroquial de San Miguel de Morón de la Frontera (Sevilla), Sevilla.

Morilla Cala, J. P. 2006, En el V Centenario de la reconstrucción de la iglesia de San Miguel. El plano, el texto y la añeja fotografía, Morón de la Frontera.

Morón de Castro, M. ${ }^{a}$ F. 1995, La iglesia de San Miguel de morón. Cinco siglos en la historia de Morón de la Frontera. XIV - XVIII, Sevilla.

Pinto Puerto, F. 2001, Las esferas de piedra. Sevilla como lugar de encuentro entre arte y ciencia del Renacimiento, Sevilla.

Sancho Corbacho, A. 1952 [1984], Arquitectura barroca Sevillana del siglo XVIII. Madrid.

Recibido: 31 de agosto de 2009

Aceptado: 26 de octubre de 2009 